\title{
Cohort Differences in Adult-Life Trajectories of Internal and External Control Beliefs: A Tale of More and Better Maintained Internal Control and Fewer External Constraints
}

\author{
Denis Gerstorf \\ Humboldt University Berlin and German Institute for Economic \\ Research (DIW) Berlin \\ Sandra Duezel \\ Max Planck Institute for Human Development, Berlin, Germany
}

Hans-Werner Wahl and Oliver K. Schilling

Heidelberg University

Jelena S. Siebert

Heidelberg University

Peter Eibich

Max Planck Institute for Demographic Research, Rostock, Germany

Gert G. Wagner

Max Planck Institute for Human Development, Berlin, Germany, and German Institute for Economic Research (DIW) Berlin

Jutta Heckhausen

University of California, Irvine
Johanna Drewelies

Humboldt University Berlin

\author{
Jacqui Smith \\ University of Michigan \\ Ute Kunzmann \\ University of Leipzig \\ Martin Katzorreck \\ University of Leipzig
}

Ilja Demuth and Elisabeth Steinhagen-Thiessen Charite - Universitätsmedizin Berlin

Ulman Lindenberger

Max Planck Institute for Human Development, Berlin, Germany, and Max Planck UCL Centre for Computational Psychiatry and Ageing Research, Berlin, Germany

Nilam Ram

Pennsylvania State University and German Institute for Economic Research (DIW) Berlin

\begin{abstract}
Life Span theory posits that sociohistorical contexts shape individual development. In line with this proposition, cohort differences favoring later-born cohorts have been widely documented for cognition and health. However, little is known about historical change in how key resources of psychosocial functioning such as control beliefs develop in old age. We pooled data from 3 independent samples:
\end{abstract}

Editor's Note. Ursula M. Staudinger served as the action editor for this article.-EALS-M

(DD Denis Gerstorf, Department of Psychology, Humboldt University Berlin, and Socio-Economic Panel, German Institute for Economic Research (DIW) Berlin; Johanna Drewelies, Department of Psychology, Humboldt University Berlin; Sandra Duezel, Center for Lifespan Psychology, Max Planck Institute for Human Development, Berlin, Germany; Jacqui Smith, Institute for Social Research, University of Michigan; Hans-Werner Wahl, Network Aging Research, Heidelberg University; Oliver K. Schilling, Institute of Psychology, Heidelberg University; Ute Kunzmann, Institute of Psychology, University of Leipzig; Jelena S. Siebert, Institute of Psychology, Heidelberg University; Martin Katzorreck, Institute of Psychology, University of Leipzig; Peter
Eibich, Research Group Labor Demography, Max Planck Institute for Demographic Research, Rostock, Germany; Ilja Demuth, Research Group Biology of Aging, Charite - Universitätsmedizin Berlin; Elisabeth SteinhagenThiessen, Department of Endocrinology and Metabolic Medicine, Charite Universitätsmedizin Berlin; Gert G. Wagner, Max Planck Institute for Human Development, and Socio-Economic Panel, German Institute for Economic Research (DIW) Berlin; Ulman Lindenberger, Center for Lifespan Psychology, Max Planck Institute for Human Development, and Max Planck UCL Centre for Computational Psychiatry and Ageing Research, Berlin, Germany; Jutta Heckhausen, Department of Psychology and Social Behavior, University of California, Irvine; Nilam Ram, Department of Human Development and Family Studies, Pennsylvania State University, and SocioEconomic Panel, German Institute for Economic Research (DIW) Berlin. 
Berlin Aging Study (6 waves, $N=414$ ); Interdisciplinary Longitudinal Study of Adult Development (4 waves, $N=925$ ); and Berlin Aging Study II (4 waves, $N=1,111$ ) to construct overlapping multiyear longitudinal data from ages 61 through 85 years for cohorts born 1905 to 1953 and examine historical changes in within-person trajectories of internal and external control beliefs. Results revealed that earlier-born cohorts exhibit age-related declines in internal control beliefs regarding both desirable and undesirable outcomes, whereas later-born cohorts perceive higher internal control and maintain this advantage into old age. Earlier-born cohorts also experience steep age-related increases in external control beliefs regarding both powerful others and chance, whereas later-born cohorts perceive lower external control and were stable across old age. Education and gender disparities in control beliefs narrowed over historical time. Sociodemographic, physical health, cognitive, and social factors explained some of the differences in control beliefs, and accounted for sizable portions of cohort effects. Our results indicate that current generations of older adults perceive more and better maintained internal control and fewer external constraints. We discuss potential underlying mechanisms and consider conceptual and societal implications of our findings.

Keywords: control beliefs, perceived control, cohort differences, historical changes, Berlin Aging Studies, ILSE

Supplemental materials: http://dx.doi.org/10.1037/pag0000389.supp

Life Span psychological and life course sociological research seeks a better understanding of how individual functioning and development are shaped by historical and sociocultural contexts (Baltes, Lindenberger, \& Staudinger, 2006; Bronfenbrenner, 1986; Elder, 1974; Mayer, 2009; Ryder, 1965; Schaie, 1965). Historical increases favoring later-born cohorts in midlife and old age are widely documented for levels of cognitive performance (Flynn, 1999; Trahan, Stuebing, Fletcher, \& Hiscock, 2014), physical health (Crimmins, 2018), and well-being (Sutin et al., 2013). Better living conditions and preserved overall functioning may allow older adults in the 2010s-relative to same-aged older adults in earlier decades - to consider themselves as more in control of their lives and less dependent on others. Empirically, however, little is known about historical changes in individuals' beliefs about personal control and about how fragile or stable control beliefs are in late life.

Our study examines cohort- and age-related differences in individuals' control belief trajectories. We pool data from three independent longitudinal studies from Germany that measured control using the same scale: (a) the Berlin Aging Study (BASE; data collected from 1990-1993 to 2005, up to six waves, $N=414$ ); (b) the Interdisciplinary Longitudinal Study of Adult Development (ILSE; data collected from 1993-1996 to 2017, up to four waves,
$N=925$ ); and (c) the Berlin Aging Study II (BASE-II; data collected from 2013-2014 to 2017, up to four waves, $N=1,111$ ). The combined, overlapping, multiyear longitudinal data provide unique opportunity for robust examination of historical changes in control belief trajectories among individuals aged 61 to 85 years in cohorts born between 1905 and 1953 .

\section{Internal and External Control Beliefs}

Inquiry in many areas of psychology has long acknowledged that control beliefs are multidimensional (Reich \& Infurna, 2016). Internal control beliefs (aka mastery beliefs, self-efficacy, and agency) are beliefs about one's capacity to bring about a given outcome (Lachman \& Weaver, 1998a; Pearlin \& Schooler, 1978). Following work on the locus of control (Levenson, 1981; Rotter, 1966; see also Skinner, 1996), internal control beliefs are beliefs about one's capacity to achieve desirable outcomes, including one's goals and the tasks of everyday life (Kunzmann, Little, \& Smith, 2002). Internal control beliefs can also reflect perceptions of personal responsibility for undesirable outcomes and, thus, be associated with feelings of guilt and lack of capability after failure or with motivation to invest more effort and diligence in the future.
This article reports data from the Berlin Aging Study (BASE; www.baseberlin.mpg.de), the Interdisciplinary Longitudinal Study of Adult Development (ILSE; http://www.psychologie.uni-heidelberg.de/ae/apa/research/ilse .html), and the Berlin Aging Study II (BASE-II; https://www.base2.mpg.de/ en). First, the BASE was initiated by the late Paul B. Baltes, in collaboration with Hanfried Helmchen, psychiatry; Elisabeth Steinhagen-Thiessen, internal medicine and geriatrics; and Karl Ulrich Mayer, sociology. Financial support came from the Max Planck Society; the Free University of Berlin; the German Federal Ministry for Research and Technology (1989-1991, 13 TA 011 \& 13 TA 011/A); the German Federal Ministry for Family, Senior Citizens, Women, and Youth (1992-1998, 314-1722-102/9 \& 314-1722-102/9a); and the BerlinBrandenburg Academy of Sciences' Research Group on Aging and Societal Development (1994-1999). Second, the ILSE was recently funded by the Dietmar Hopp Stiftung (2013-2017) and has previously been funded by the Federal Ministry of Family Affairs, Senior Citizens, Women and Youth (AZ:
301-1720-295/2 und 301-6084/035). Third, the BASE-II research project (Co-PIs are Lars Bertram, Ilja Demuth, Denis Gerstorf, Ulman Lindenberger, Graham Pawelec, Elisabeth Steinhagen-Thiessen, and Gert G. Wagner) is supported by the German Federal Ministry of Education and Research (Bundesministerium für Bildung und Forschung, BMBF) under Grants 16SV5536K, 16SV5537, 16SV5538, 16SV5837, 01UW0808; 01GL1716A; and 01GL1716B. Another source of funding is the Max Planck Institute for Human Development, Berlin, Germany. Additional contributions (e.g. equipment, logistics, and personnel) are made from each of the other participating sites.

Correspondence concerning this article should be addressed to Denis Gerstorf, Department of Psychology, Humboldt University Berlin, Unter den Linden 6, 10099 Berlin, Germany. E-mail: denis.gerstorf@huberlin.de 
In complement, external control beliefs are beliefs about personal constraints. They denote that some outcomes can be beyond one's personal control because powerful others in one's personal, social, or professional life (e.g., spouse, caregiver, or supervisor) or external conditions (e.g., politics, economy, and war) determine relevant aspects of one's life or because the good or bad things in (one's) life happen by chance, fate, or luck. In summary, there are a minimum of four distinct, yet interrelated dimensions of control beliefs: internal control beliefs over desirable outcomes, internal control beliefs over undesirable outcomes, external control beliefs in powerful others, and external control beliefs in chance.

\section{Age Trajectories of Control Beliefs}

Empirical work has examined age-related change in a variety of control-related beliefs (Brandtstädter, 1989; Brandtstädter \& Rothermund, 1994; Lachman \& Weaver, 1998b). For example, longitudinal and cross-sectional studies of broadly defined perceived personal control indicate an increase until midlife, a plateau at midlife, and a decline thereafter that accelerates beyond age 70 (Drewelies, Wagner, Tesch-Römer, Heckhausen, \& Gerstorf, 2017; Mirowsky \& Ross, 2007). Our report builds on this prior work and examines longitudinal age gradients in four dimensions of control beliefs.

Age trajectories on internal control over desirable or undesirable outcomes may differ. Perceptions of control over desirable outcomes are related to the controllability of individuals' goals. Motivational and action theories of developmental regulation (Brandtstädter \& Rothermund, 2002; Freund \& Baltes, 1998; Heckhausen, Wrosch, \& Schulz, 2019) propose that older adults maintain a sense of internal control by disengaging from the goals they can no longer achieve and by focusing their remaining resources onto fewer cherished life goals as they adjust to health and social losses. This would lead to stability or only minor decline in older adults' internal control beliefs about desirable outcomes. In contrast, for control beliefs about undesirable outcomes, previous research on beliefs about undesirable psychological changes (e.g., forgetfulness) showed that, compared with younger adults, older adults report having less control (Heckhausen \& Baltes, 1991). Because the frequency and severity of uncontrollable outcomes in the health and social domains increases with age, it is adaptive for older adults to let go of and disengage from perceiving oneself to be in charge of such outcomes (Heckhausen et al., 2019). This would lead to age-related declines in internal control beliefs over undesirable outcomes.

Motivational theories suggest that external control beliefs in powerful others increase in old age because the functional limitations that often accompany old age require that other people (e.g., adult children, caregivers, health care providers) become more relevant and instrumental for goal attainment. For external control beliefs in chance and (bad) luck, accumulated life experience would indicate a greater role of uncontrollable external factors, so that luck figures more prominently in the control beliefs of older adults. With age-related increases in the risk for experiencing negative events, it is adaptive for older adults to make use of self-regulatory strategies that attribute uncontrollable outcomes to fate, destiny, or fortune (Krause, 2005). In this study, we examine whether these age trajectories are modulated by the historical times people are living in.

\section{Historical Change and Control Beliefs}

The study of cohort differences in perceptions of control is important for a number of reasons. To begin with, control beliefs are a key psychosocial resource for successful aging (Baltes \& Baltes, 1986; Rowe \& Kahn, 1997; Ryff \& Singer, 1998) and constitute a general purpose mechanism of adaptation that serves as an important resource people draw from when dealing with challenges. If access to such a resource has changed historically, older adults may be in a better position today to deal with the challenges they are confronted with. Similarly important, control beliefs are known to be predictive of major life outcomes, including physical health and mortality (Infurna, Ram, \& Gerstorf, 2013). History-graded changes in control beliefs may be helping older adults live healthier and longer lives.

We have identified five sets of conceptual arguments for why cohort differences in control beliefs have emerged. First, early life experiences differ across generations both within and across countries. For example, the biographies of people born in the first decades of the 20th century in Germany have been shaped by major events and experiences over which the majority of people had no or very little personal control, including WW1, Nazi Regime, the Great Depression, and WW2 (Elder \& George, 2016; Hülür et al., 2016; Maas, Borchelt, \& Mayer, 1999).

Second, more recent societal trends of de-traditionalization and individualization (Greenfield, 2009; Santos, Varnum, \& Grossmann, 2017) suggest that people in contemporary western societies are socialized to be more independent, more actively influence their own destiny, and enjoy greater freedom from the confines of external forces than people of the same age several decades ago (see Twenge, Zhang, \& Im, 2004). Exercising control is societally valued, fostered through current living conditions, and constitutes a basic skill to master the challenges, societal expectations, and developmental tasks of modern life.

Third, theoretical models acknowledging manifold dynamics suggest that control beliefs are shaped by functioning and development in other key areas of life (Antonucci, 2001; Lachman, 2006). Historical improvements in functional and cognitive health among older adults today relative to same-aged peers several decades ago may, thus, have contributed to historical changes in control beliefs. For example, because contemporary cohorts of older adults show improved physical and cognitive functioning (Gerstorf et al., 2015; König et al., 2018), they might be in a better position to indeed exert control over their lives-thereby maintaining internal control beliefs into higher ages and showing less pronounced increases in external control beliefs.

Fourth, the arguments noted assume that historical changes have increased objective control capacities, which are to some extent mirrored in subjective control perceptions. However, control perceptions are often not isomorphic reflections of actual capacities. Research on children and young adults suggests that U.S. Americans report more internal control beliefs and agency than those in Germany and their control beliefs are more strongly removed from actual capacity (Little, Oettingen, Stetsenko, \& Baltes, 1995). Applied to historical change among older adults, it is possible that non-U.S. citizens also increasingly exhibit a growing discrepancy between the actual capacities people have and the control perceptions they hold, and by implication more internal control beliefs. The arguments reviewed so far each suggest that later-born cohorts 
exhibit more internality and less externality than earlier-born cohorts.

A fifth and final argument in contrast suggests reduced control beliefs across cohorts and notes that individualization and modernization also come with psychological costs, for example, if life is perceived as less predictable and less controllable (Twenge et al., 2004). To illustrate, increased geographic mobility and demographic change mean that the close social connections and support structures that people have relied on in past decades to master their life challenges and need for support have diminished (Ryan, Smith, Antonucci, \& Jackson, 2012). Similarly, greater alienation from one's community among more recent generations (Fukuyama, 1999) along with growing uncertainty, less confidence, and more distrust into society (Pharr, Putnam, \& Dalton, 2000; Twenge \& Campbell, 2010) suggest that later-born generations may report lower internal control beliefs and higher external control beliefs.

Empirical studies have shown that levels of control beliefs have indeed changed over historical time (Drewelies, Agrigoroaei, Lachman, \& Gerstorf, 2018; Drewelies, Deeg, Huisman, \& Gerstorf, 2018; Hülür et al., 2016; Twenge et al., 2004). However, the direction of change is equivocal, in part because of differences in the countries examined and age group studied. For example, in 2011 in the United States, only 36\% of adults agreed with the statement that "success in life is determined by forces outside our control," whereas in Germany $72 \%$ of adults agreed with the statement (Kohut et al., 2011). Twenge and colleagues (2004) reported from two meta-analyses that levels of an external locus of control exhibited substantial historical increases among child (age 9 to 14 years) and college student samples (in their 20s) between the 1960s and the 2000s. Similarly, young adults in the United States (aged 23 to 39 years) in later-born cohorts reported more constraints and external control than their age peers 18 years ago and also reported less mastery and internal control (Drewelies, Agrigoroaei, et al., 2018). By contrast, older adults in the United States (aged 65 to 75 years) perceived substantially fewer constraints and external control than their same-aged peers two decades ago. The same pattern of differences in levels of external control beliefs was reported for adults in late midlife in the Netherlands (aged 55 to 65 years: Drewelies, Deeg, et al., 2018) and older adults in Germany (aged 65 to 89 years: Hülür et al., 2016). Our study moves forward from considering cross-sectional time-lag differences in select dimensions of control beliefs to examine historical changes in within-person longitudinal change trajectories of multiple control belief dimensions across adulthood and old age.

\section{The Role of Socio-Demographic, Physical Health, Cognitive, and Social Factors}

A variety of sociodemographic, health, cognitive, and social factors likely contribute to individual and cohort-related differences in age trajectories of control beliefs (Antonucci, 2001; Lachman, 2006). Some of these correlates were available and assessed in identical ways across the three studies pooled together in our report. First, more educated people often report higher internal and lower external control beliefs, presumably because they can indeed exercise more control over their lives, for example by having access to higher-level careers (Mirowsky \& Ross, 2007). Historical increases in the quantity and quality of education
(Bauernschuster \& Falck, 2015; Schaie, 2008) may contribute to older adults today reporting more favorable age trajectories in perceptions of control. Similarly, increased participation of women in (higher) education and the workforce have reduced gender disparities (Shockley \& Shen, 2015) and may mean that the lower internal and higher external control beliefs observed among women (Gatz \& Karel, 1993) are less pronounced today.

The prevalence of particular diseases is rising, but common diseases have become less disabling (Crimmins, 2018; but see Salomon et al., 2012). Because morbidity and functional limitations often undermine daily functioning (Heckhausen, Wrosch, \& Schulz, 2013), poor health is typically associated with lower internal and higher external control beliefs (Drewelies et al., 2017). Better health among later-born cohorts may contribute to more favorable age trajectories of control beliefs (Deeg \& Huisman, 2010).

Older adults today outperform same-aged peers tested several decades ago on cognitive ability tests (Schaie, 2005) and exhibit fewer age decrements (Gerstorf, Ram, Hoppmann, Willis, \& Schaie, 2011; Lindenberger, 2014). Because cognitive functioning is closely linked with perceptions of control (Lachman, 2006), historical increases in cognitive functioning may contribute to historical increases in internal control beliefs and decreases in external control beliefs.

Rates of marriage have declined over time, and many first marriages now end in divorce (Cherlin, 2010). In the past, differences in marital status and associated factors such as social support and economic security have long been linked to perceptions of control. For example, married men typically report higher internal control beliefs, whereas marriage often reduces autonomy and control among women (Ross \& Mirowsky, 2013). Also, people who have experienced divorce often report lower internal control beliefs (Machida \& Holloway, 1991) than married age peers. Consistent with historical changes in other outcomes (e.g., fewer increases in loneliness with divorce in more recent generations; van Tilburg, Aartsen, \& van der Pas, 2015), historical changes in marriage norms may reduce differences in perceptions of control observed earlier.

\section{The Present Study}

Drawing from and extending earlier work on historical changes in levels of control beliefs (Drewelies, Agrigoroaei, et al., 2018; Drewelies, Deeg, et al., 2018; Hülür et al., 2016; Twenge et al., 2004), the current study examines cohort differences in withinperson change trajectories of control beliefs across the second half of life. We pool longitudinal within-person change data obtained in three independent studies in Germany, BASE (up to six waves for $N=414$ ); ILSE (up to four waves for $N=925$ ); and BASE-II (up to four waves for $N=1,111$ ). Based on conceptual considerations and empirical reports of multidimensionality of control beliefs (Lachman \& Weaver, 1998b; Levenson, 1981; Rotter, 1966; Skinner, 1996), we consider four dimensions: Internal control beliefs over either desirable or undesirable outcomes and external control beliefs in either powerful others or chance. We expect higher internal control and lower external control beliefs among more recent cohorts of older adults and also assume that age-related reductions in internal control and age-related increases in external control beliefs become less pronounced over historical time. We 
will explore whether and how the size of historical changes differs between the two internal control dimensions and between the two external control dimensions examined. We will also quantify the role of sociodemographic, physical health, cognitive, and social factors for cohort differences in age trajectories of control beliefs and assume those to account for sizable shares of the cohort effects to be observed in control beliefs. Finally, we explore whether education and gender disparities in control beliefs documented in the past have narrowed.

\section{Method}

\section{Participants and Procedure}

Examination of cohort differences was facilitated by merging data from the BASE, ILSE, and BASE-II studies. Descriptions of participants, variables, and procedures for each study are reported in previous publications (BASE: Baltes \& Mayer, 1999; Lindenberger, Smith, Mayer, \& Baltes, 2010; ILSE: Sattler et al., 2017; BASE-II: Bertram et al., 2014; Gerstorf et al., 2016). Ethics approval for BASE was granted by the Berlin Medical Association, for ILSE by the ethics committee of the Medical Faculty of Heidelberg, and for BASE-II by the ethics committees of the Charité-Universitätsmedizin Berlin and the Max Planck Institute for Human Development, Berlin. Further approval was audited by the funding sources.

A brief two-paragraph description of each study design and sample is provided in the online supplemental material. As shown in Table 1, the studies have several design features in common. Each study assessed perceived control four times or more over a period of five or more years. The studies also differ from one another. We capitalize on these differences in study design to examine cohort differences. First, the three studies started at different historical times, BASE in the early 1990s, ILSE in the mid-1990s, and BASE-II in the early 2010s. Second, the three studies recruited participants born in different years, from the turn of the 20th century to the 1950 s. Third, the three studies recruited participants of different ages, some provided data in their early 40 s (the later-born ILSE cohort), others in their early 60s (the earlierborn ILSE cohort), early 70s (BASE-II), or mid-80s (BASE). Finally, these studies and samples also differ on factors such as location and experience (political and education systems) - differences that are addressed analytically.

\section{Measures}

Internal and external control beliefs. The four control belief dimensions were assessed in the same way in all three studies using items derived from conceptual and empirical work on locus of control (Kunzmann et al., 2002; Levenson, 1981). For each dimension, participants were asked to indicate the extent to which they agreed with three or four statements, using a 5-point Likertscale from $1=$ does not apply to me at all to $5=$ applies very well to me.

Sample items include "I can make sure that good things come my way." (internal control beliefs over desirable outcome, Cronbach's $\alpha \geq .68$ across studies); "It's my fault if something goes wrong in my life." (internal control beliefs over undesirable outcomes, Cronbach's $\alpha \geq .67$ ); "The good things in my life are determined by other people." (external control beliefs in powerful others, Cronbach's $\alpha \geq$.77); and "The good things in my life are, for the most part, a matter of luck." (external control beliefs in chance, Cronbach's $\alpha \geq .57$ ). Full item wordings are listed in the online supplemental material.

Item correlations for three out of our four major outcome variables were somewhat low, but are similar to those reported in other studies (e.g., Brandtstädter \& Rothermund, 1994: Cronbach's $\alpha$ between .66 and .74; see also Jopp \& Schmitt, 2010; Rubio, Dumitrache, \& Cordón-Pozo, 2018; Wallston, Wallston, \& DeVellis, 1978). These psychometric properties reflect the brief nature of the scales ( 3 or 4 items) and the purposeful use of heterogeneous items that sample across the construct space (i.e., items are not all asking exactly the same thing; Boyle, 1991). This approach is analogous to the brief assessments of Big Five personality traits in large-scale surveys (see Lucas \& Donnellan, 2011; Mueller, Wagner, Wagner, Ram, \& Gerstorf, 2019). ${ }^{1}$ Scores for the four dimensions were transformed to a T-standardized metric using baseline data of the entire sample $(M=50, S D=10)$.

Sociodemographic, physical health, cognitive, and social factors. A selection of person-level variables was extracted from each study. Where necessary, scores were converted to a common metric. Sociodemographic variables included one binary variable for sex, woman $(=1)$ or man $(=0)$. Education was measured as the number of years spent in formal schooling. Because historical changes in education map the socioeconomic distribution differently across cohorts, a person with a high school degree (that was not common in earlier-born cohorts) might have been more successful in finding employment in earlier-born cohorts as compared with later-born cohorts for whom many jobs have required a college degree. To obtain better measurement equivalence, years of education were standardized separately for each sample and cohort using reference data (population means and SDs) from the nationally representative German Socio-Economic Panel (SOEP; Headey, Muffels, \& Wagner, 2010). The following reference populations were used: BASE, 70+ year old Germans in 1990 when the study commenced ( $M=10.69$ years of education, $S D=2.06)$; older ILSE sample, 61- to 63-year olds in $1993(M=10.95, S D=$ 2.47); younger ILSE sample, 41- to 43-year olds in 1993 ( $M=$

\footnotetext{
${ }^{1}$ Corroborating the point, applying the Spearman-Brown formula revealed that if 10 items were available, rather than the current three or four items, Cronbach's $\alpha$ would have been .77 for external control beliefs in chance and above .85 for the other three scales. Thus, we consider it permissible to prioritize construct breadth. In line with contemporary views on Cronbach's $\alpha$ (see Cho \& Kim, 2015), we also estimated a series of follow-up analyses in which we calculated for each control belief dimension a confirmatory factor analysis with the respective items as indicators of a latent factor, and examined how the latent scores correlated with the unit-weighted composite scores used in our main analyses. The correlations were $r=.83$ for internal control beliefs over desirable outcomes, $r=.94$ for internal control beliefs over undesirable outcomes, $r=.84$ for external control beliefs in powerful others, and $r=.95$ for external control beliefs in chance. This suggests that even though the Cronbach's $\alpha$ of the unitweighted composite is rather low, we capture the same interindividual differences that would be captured by a purified latent factor. That is, the correlations support our use of the unit-weighted composites. These composites introduce some error (because reliabilities are less than 1), but this is tolerable and would mean that our results with the composites are a rather conservative (because the relations with other variables are assessed in the presence of some measurement error).
} 
Table 1

Overview of the Three Independent Studies Used in This Report

\begin{tabular}{lccc}
\hline \multicolumn{1}{c}{ Variables } & Berlin Aging Study & ILSE & Berlin Aging Study II \\
\hline Location & Berlin & Heidelberg, Leipzig & Berlin \\
Years started & $1990-1993$ & $1993-1996$ & $2013-2014$ \\
Waves & 6 & 4 & 4 \\
Max. years in study & 13 & 23 & 5 \\
Years between waves & $99-4.03$ & $3.85-8.57$ & $1.09-1.64$ \\
$N$ at T1 & 414 & 925 & 1,112 \\
Birth years & $1889-1922$ & $1930-32,1950-52$ & $1925-1953$ \\
$M$ age at T1 $(S D)$ & $84(8.3)$ & $44(.9), 63(.9)$ & $70(3.6)$ \\
\%women & 46 & 49,49 & 51 \\
$M$ education & 10.9 & $12.8,14.0$ & 14.6 \\
\hline
\end{tabular}

Note. $\quad$ ILSE = Interdisciplinary Longitudinal Study of Adult Development.

11.88, $S D=2.76)$; and BASE-II, $60+$ year olds in $2010(M=$ $11.83, S D=2.72$ )

Grip strength, a general measure of physical health (upper-body functioning), was assessed with standard protocol as the maximum force applied to a hand dynamometer across six trials, three per hand. Differences in scale units and scale usage across studies (e.g., BASE: force measured in kilogram vs. ILSE: pressure measured in $\mathrm{kPa}$ ) were accommodated using a percent of maximum possible (POMP; Cohen, Cohen, Aiken, \& West, 1999) approach (BASE: $\max =35 \mathrm{~kg}$; ILSE: $\max =174.75 \mathrm{kPa}$; BASE-II: $\max =62.17 \mathrm{~kg}$ ).

Cognitive performance was measured in each study using the Digit Symbol Substitution test (Wechsler, 1955). The test consists of a code box with nine digit-symbol pairs where each digit is paired with a corresponding symbol, and rows of double boxes with a digit in the top box and an empty lower box. Participants were asked to fill in as many corresponding symbols as possible in $90 \mathrm{~s}$. Scores indicate the number of correctly filled boxes, with penalty for wrong answers (score $=$ total-wrong). ILSE used a slightly different but comparable version of the test from the Nuremberg Inventory of Old Age (Oswald \& Fleischmann, 1995), where the nine pairs consist of five digit-symbol pairs and four digit-letter pairs. Scores were converted to a POMP unit based on the maximum possible score (74 in the two Berlin Aging Studies; 67 in ILSE). Although the three studies assessed cognition in multiple ways, the Digit Symbol was the only cognitive test administered in a similar way in each study.

Two measures of marital status were common in all three studies: Being married $(=1)$ or not $(=0)$; and whether an individual got divorced at any point during their study participation $(=1)$ or not $(=0)$.

Time-in-study, age, and cohort. Intraindividual change was examined as time-in-study, a time-varying variable quantified for each assessment as the number of years since baseline (T1) and centered at the middle of each individual's repeated measures time-series. Agerelated differences (age gradients) were examined as individuals' chronological age (at their middle assessment) and centered at age 70 years, close to the average age of the sample. Cohort-related differences were examined as individuals' birth year, centered at 1925 so as to use earlier-born generations as the point of reference.

For graphical illustration purposes only, individuals were placed into three birth cohort "groups": those born before $1930(n=418)$, those born between 1930 and $1944(n=1,167)$, and those born between 1945 and $1953(n=865)$. Acknowledging that cohort group cutoffs are arbitrary, our grouping was selected to maximize overlap in age between the three birth-year cohorts. As shown in Figure 1, each birth cohort encompassed more than 400 participants who contributed more than 850 data points that spanned 25 years of age and more. There were overlapping observations between ages 61 and 73 years for the 1930-1944 and 1945-1953 cohorts; between ages 70 and 85 years for the cohort born before 1930 and those born 1930-1944; and between ages 70 and 73 years for the cohort born before 1930 and those born 1945-1953.

\section{Data Analysis}

Intraindividual changes, age-related, and history-related differences were examined using growth models (Ram \& Grimm, 2015; Raudenbush \& Bryk, 2002; Singer \& Willett, 2003), specified for each of the four dimensions as

$$
\begin{aligned}
{\text { control belief } s_{t i}=} & \beta_{0 i}+\beta_{1 i}\left(\text { timeinstud } y_{t i}\right) \\
& +\beta_{2 i}\left(\text { timeinstud } y_{t i}^{2}\right)+e_{t i}
\end{aligned}
$$

where person i's score on a given control beliefs dimension at observation $t$, control beliefs $s_{t i}$, is modeled as a function of a person-specific intercept coefficient, $\beta_{0 i}$; a person-specific linear slope coefficient, $\beta_{1 i}$; a person-specific quadratic slope coefficient, $\beta_{2 i}$; and residual error, $e_{t i}$. Individual differences in the personspecific coefficients were modeled as

$$
\begin{gathered}
\beta_{0 i}=\gamma_{00}+\gamma_{01}\left(\text { age }_{i}\right)+\gamma_{02}\left(\text { BASE }_{i}\right)+\gamma_{03}(\text { BASE2 }) \\
+\gamma_{04}\left(\text { birthyear }_{i}\right)+\gamma_{05}\left(\text { birthyear }_{i} * \text { age }_{i}\right)+u_{0 i} \\
\beta_{1 i}=\gamma_{10}+\gamma_{11}\left(\text { age }_{i}\right)+\gamma_{12}\left(\text { birthyear }_{i}\right) \\
+\gamma_{13}\left(\text { birthyear }_{i} * \text { age }_{i}\right)+u_{1 i}, \\
\beta_{2 i}=\gamma_{20},
\end{gathered}
$$

where $\gamma s$ are sample-level parameters, BASE and BASE2 are dummy variables indicating study of origin (with ILSE serving as reference category), and $u_{0 i}$ and $u_{1 i}$ are unexplained individual differences that are assumed multivariate normally distributed with variances, $\sigma_{u 0}^{2}$ and $\sigma_{u 1}^{2}$, and covariance $\sigma_{u 0 u 1}$. Given the scarcity of repeated measures, random coefficients for and predictors of quadratic slopes, $\beta_{2 i}$, were not reliably different from zero and, thus, were not included in the final models. 


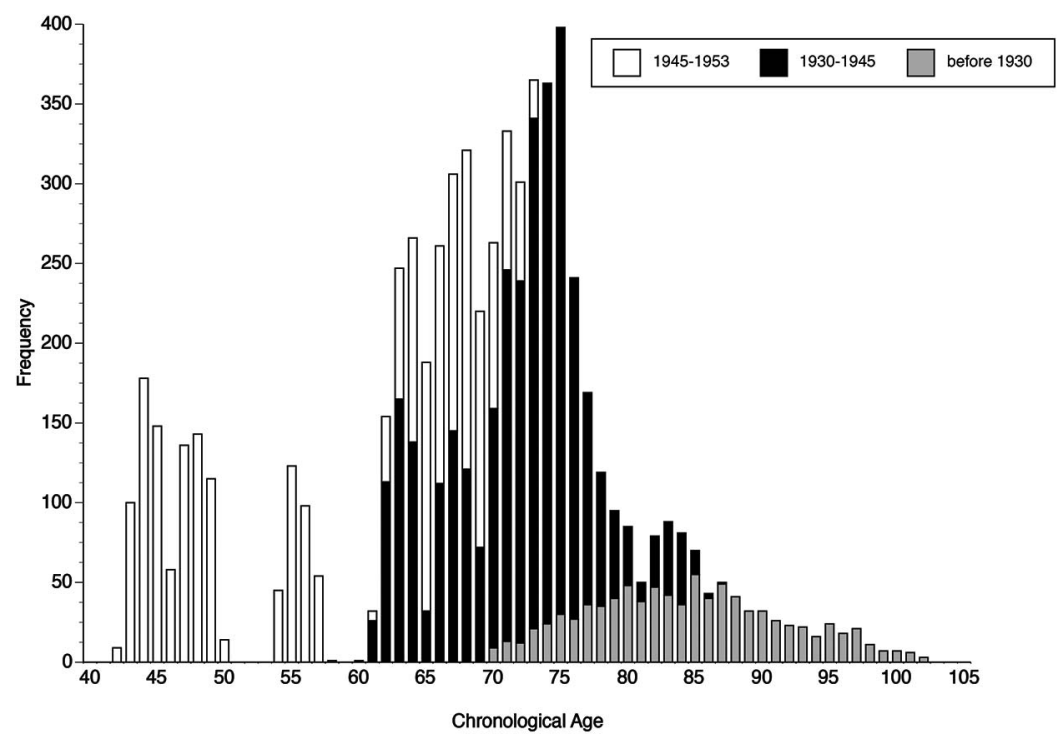

Figure 1. Frequency of observations across chronological age separately for the three birth cohorts as pooled across data obtained in the Berlin Aging Study (BASE), the Interdisciplinary Longitudinal Study of Adult Development (ILSE), and the Berlin Aging Study II (BASE-II). Each birth cohort encompassed more than 400 participants who contributed more than 850 data points that spanned 25 years of age and more. Age trajectories exhibited considerable overlap between the three birth cohorts: From age 61 years to age 73 years for the 1930-1944 and 1945-1953 cohorts; from age 70 years to age 85 years for the cohort born before 1930 and those born 1930-1944; and from age 70 years to age 73 years for the cohort born before 1930 and those born 1945-1953.

The role of sociodemographic, physical health, cognitive, and social factors was examined by including these variables as additional predictors of the person-specific intercepts and linear rates of change, $\beta_{0 i}$ and $\beta_{1 i}$, with all interaction terms with the cohort variable included. To maintain parsimony, however, only statistically significant interactions were maintained in the final models. Person-level predictors were effect-coded/centered so that parameters indicated the average trajectory and the extent of differences associated with a particular variable (rather than for a particular group). Models were fit to the data using SAS (Proc Mixed; Littell, Milliken, Stroup, Wolfinger, \& Schabenberger, 2006). Incomplete data were accommodated under usual missing at random assumptions (Little \& Rubin, 1987), with included variables (e.g., age, health, and cognition) serving as attrition-informative variables that alleviate longitudinal selectivity for the outcome variables (Grimm, Ram, \& Estabrook, 2016; McArdle, 1994).

\section{Follow-Up Analyses}

There was substantial overlap in individuals' birth year, study of origin, and year of first assessment $(r=.74, .57$, and .93, respectively), which made it difficult to disentangle birth-year effects from study effects, the latter possibly "carrying" period effects (i.e., test-year effects). Acknowledging that it is not possible to separate age, cohort, and period effects (Bell \& Jones, 2015; Schaie, 1965), we conducted a variety of follow-up analyses to alleviate concerns that (parts of) the observed cohort differences were driven by differences-including test-period differencesbetween the studies being combined. First, we checked for acrossstudy homogeneity by identifying subgroups of participants from different studies who were tested at the same chronological age and point in historical time and examining whether the two subsamples from different studies of origin and location differed on our outcome variables. Second, we reran all models with just the two Berlin-based samples for which comparability has been documented (Gerstorf et al., 2015; Hülür et al., 2016; König et al., 2018). Finally, we included an additional control variable indicating whether an individual had lived in West Germany or East Germany to account for the possibility of distinct socialization experiences relevant for perceptions of control (in childhood; Oettingen, Little, Lindenberger, \& Baltes, 1994).

\section{Results}

\section{Descriptive Analyses}

Descriptive statistics and intercorrelations among the measures of interest are reported in Table 2. The four dimensions of control beliefs show only moderately sized intercorrelations, with the two dimensions of internal control beliefs (correlated $r=.36$ ) being independent or negatively related to the two dimensions of external control beliefs (that were correlated $r=.40$ ). This suggests that the four measures of control beliefs capture different aspects of the larger concept space and that reporting high internal control beliefs does not necessarily go hand in hand with reporting low external control beliefs. In addition, birth year was negatively related to external control beliefs (e.g., $r=-.38$ with beliefs in powerful others), whereas age was positively related to external control beliefs (e.g., $r=.21$ with beliefs in powerful others). Generally, control beliefs were related to the sociodemographic, health, cognitive, and social factors in expected ways (Caplan \& Schooler, 
Table 2

Descriptive Statistics at Baseline Assessment and Intercorrelations for Study Measures

\begin{tabular}{|c|c|c|c|c|c|c|c|c|c|c|c|c|c|}
\hline \multirow[b]{2}{*}{ Variables } & \multirow[b]{2}{*}{$M$} & \multirow[b]{2}{*}{$S D$} & \multicolumn{11}{|c|}{ Intercorrelations } \\
\hline & & & 1 & 2 & 3 & 4 & 5 & 6 & 7 & 8 & 9 & 10 & 11 \\
\hline (1) Internal control desirable outcomes (1-5) & 3.75 & .66 & 1 & & & & & & & & & & \\
\hline (2) Internal control undesirable outcomes (1-5) & 3.48 & .74 & .36 & 1 & & & & & & & & & \\
\hline (3) External control in powerful others (1-5) & 1.84 & .74 & -.15 & -.07 & 1 & & & & & & & & \\
\hline (4) External control in chance (1-5) & 2.65 & .75 & -.20 & .01 & .40 & 1 & & & & & & & \\
\hline (5) Year of birth (1889-1953) & 1936 & 15.05 & .08 & .00 & -.38 & -.39 & 1 & & & & & & \\
\hline (6) Age (42-102) & 66.12 & 13.13 & -.04 & -.02 & .21 & .27 & -.76 & 1 & & & & & \\
\hline (7) $\%$ Women & \multicolumn{2}{|c|}{49.53} & -.06 & -.15 & .00 & .11 & .03 & -.00 & 1 & & & & \\
\hline (8) Education $(-1.78-3.06)$ & .76 & 1.13 & .00 & .02 & -.12 & -.23 & .26 & -.12 & -.17 & 1 & & & \\
\hline (9) Grip strength (0-100) & 48.66 & 18.77 & .06 & .09 & -.18 & -.21 & .46 & -.37 & -.51 & .21 & 1 & & \\
\hline (10) Digit symbol (0-100) & 60.46 & 19.42 & .02 & -.01 & -.28 & -.29 & .64 & -.67 & .11 & .31 & .27 & 1 & \\
\hline (11) $\%$ Married at $\mathrm{T} 1$ & \multicolumn{2}{|c|}{56.88} & .01 & .01 & -.05 & -.16 & .20 & -.26 & -.27 & .14 & .26 & .18 & 1 \\
\hline (12) \% Divorced & \multicolumn{2}{|c|}{21.05} & .04 & .01 & -.09 & .01 & .17 & -.04 & .17 & -.01 & -.03 & .06 & -.54 \\
\hline
\end{tabular}

Note. $\quad N=2,450$. Scores for control beliefs reported for baseline assessment at T1. Education $=$ cohort-normed education. Intercorrelations of $|r|=.05$ or above differ statistically significantly from zero at $p<.01$.

2003; Lachman, 2006). For example, those with lower cohortnormed education reported more beliefs in powerful others $(r=-.12)$ and in chance $(r=-.23)$ and those with better functional health and cognitive functioning reported fewer beliefs in powerful others $(r=-.18$ and $r=-.28)$ and in chance $(r=-.21$ and $r=-.29)$. As one would expect, the grip strength and Digit Symbol tests exhibited sizable intercorrelations with one another $(r=.27)$ as well as with chronological age $(r=-.37$ and $r=-.67$, respectively) and cohort-normed education $(r=.21$ and $r=.31$, respectively). In summary, the pattern of correlations indicates that the measures work as expected from prior literature.

\section{Historical Changes in Age Trajectories of Internal and External Control Beliefs}

Results from the initial growth models are shown in Table 3. Model 1 constitutes the basic model that treats the combined sample as a single age-heterogeneous sample to examine intraindividual change over time-in-study and age-related differences therein. Model 2 adds in cohort-related differences. As expected based on the literature (e.g., Drewelies et al., 2017), the prototypical person exhibited relative within-person stability in the two dimensions of internal control beliefs over time-in-study (desirable outcomes: $\gamma_{10}=0.020$, undesirable outcomes: $\gamma_{10}=-0.049$, both $p \mathrm{~s}>.10$ ) and in external control beliefs in chance $\left(\gamma_{10}=-0.018, p>.10\right)$. In contrast, the prototypical person's external control beliefs in powerful others increased over time-instudy $\left(\gamma_{10}=0.229, p<.001 ; \gamma_{20}=0.014, p<.001\right)$. Also as expected, there was evidence of an age gradient, with older age being associated with lower levels on internal control beliefs over desirable outcomes $\left(\gamma_{01}=-0.050, p<.001\right)$, higher levels on both external control dimensions (powerful others: $\gamma_{01}=0.234$, $p<.001$; chance: $\left.\gamma_{01}=0.231, p<.001\right)$, and steeper increases in external control beliefs in powerful others $\left(\gamma_{11}=0.022, p<\right.$ $.001)$.

In Model 2, we parsed how these trajectories differed by birth year (cohort differences), controlling for study of origin differences. As seen in the lower portion of Table 3, BASE participants reported higher external control beliefs in powerful others $\left(\gamma_{02}=\right.$ 3.928, $p<.001)$ and BASE-II participants reported higher external control beliefs in chance $\left(\gamma_{03}=3.238, p=.015\right)$. Accommodating these study differences, results revealed that a 70-year old person born in 1925 (the reference group as per our centering) experienced declines in the two dimensions of internal control beliefs (desirable outcomes: $\gamma_{10}=-0.156, p<.001$; undesirable outcomes: $\left.\gamma_{10}=-0.186, p<.001\right)$ and increases in external control beliefs in powerful others $\left(\gamma_{10}=0.275, p<.001\right)$. Again, we found evidence for age gradients and (sample) selection. Relative to younger participants, those who were older had higher levels of internal control beliefs over desirable outcomes $\left(\gamma_{01}=0.134, p<\right.$ $.001)$, less steep declines on both internal control beliefs dimensions $\left(\gamma_{11}=0.025, p<.001\right.$ and $\gamma_{11}=0.019, p<.001$, respectively), steeper increases on external control beliefs in powerful others $\left(\gamma_{11}=0.017, p=.004\right)$, and lower $\left(\gamma_{01}=-0.285\right.$, $p<.001)$ and less steep increases $\left(\gamma_{11}=-0.015, p=.002\right)$ in external control beliefs in chance.

Most important for our research questions, several birth year effects emerged. As seen in the left side of Table 3, later birth year was associated with higher levels of internal control beliefs over both desirable outcomes $\left(\gamma_{04}=0.164, p<.001\right)$ and undesirable outcomes $\left(\gamma_{04}=0.041, p=.034\right)$ at age 70 , and less pronounced intraindividual declines in internal control beliefs over both desirable outcomes $\left(\gamma_{12}=0.025, p<.001\right)$ and undesirable outcomes $\left(\gamma_{12}=0.020, p<.001\right)$. These cohort differences are depicted in Figure 2. For each cohort, the figure shows model-implied withinperson changes over 5 years in $25+$ age bins of 1-year age increments as short, thick lines. The single linear age and selection trend for each cohort is shown as long, thin line. In both panels, the earlier-born cohort (dashed lines) exhibited intraindividual declines over time-in-study in internal control beliefs (short dashed lines mostly pointing downward), whereas later-born cohorts (solid black and gray lines) reported higher levels of internal control beliefs and maintained these over time-in-study. If anything, later-born individuals' internal control beliefs increased over time-in-study (short solid black and gray lines mostly pointing upward). 
Table 3

Growth Models of Control Beliefs: The Role of Age and Year of Birth

\begin{tabular}{|c|c|c|c|c|c|c|c|c|}
\hline \multirow[b]{3}{*}{ Parameter } & \multicolumn{4}{|c|}{ Internal control beliefs over } & \multicolumn{4}{|c|}{ External control beliefs in } \\
\hline & \multicolumn{2}{|c|}{ Desirable outcomes } & \multicolumn{2}{|c|}{$\begin{array}{l}\text { Undesirable } \\
\text { outcomes }\end{array}$} & \multicolumn{2}{|c|}{ Powerful others } & \multicolumn{2}{|c|}{ Chance } \\
\hline & Est. & $S E$ & Est. & $S E$ & Est. & $S E$ & Est. & $S E$ \\
\hline \multicolumn{9}{|c|}{ Model 1} \\
\hline \multicolumn{9}{|l|}{ Fixed effects } \\
\hline Intercept $\gamma_{00}$ & $50.496^{*}$ & .178 & $50.068^{*}$ & .179 & $50.133^{*}$ & .176 & $49.812^{*}$ & .176 \\
\hline Time $\gamma_{10}$ & .020 & .027 & -.049 & .027 & $.229^{*}$ & .024 & -.018 & .024 \\
\hline $\operatorname{Time}^{2} \gamma_{20}$ & -.007 & .004 & .002 & .004 & $.014^{*}$ & .003 & .006 & .003 \\
\hline Age $\gamma_{01}$ & $-.050^{*}$ & .015 & -.004 & .015 & $.234^{*}$ & .015 & $.231^{*}$ & .015 \\
\hline Age $\times$ Time $\gamma_{11}$ & .000 & .002 & -.001 & .002 & $.022^{*}$ & .002 & .000 & .002 \\
\hline \multicolumn{9}{|l|}{ Random effects } \\
\hline Var. intercept & $49.311^{*}$ & 2.028 & $47.436^{*}$ & 2.028 & $54.091^{*}$ & 2.104 & $52.343^{*}$ & 2.017 \\
\hline Var. time & $.057^{*}$ & .019 & .031 & .020 & $.066^{*}$ & .017 & .028 & .014 \\
\hline Cov. Intercept, time & $.548^{*}$ & .190 & .260 & .181 & $.881^{*}$ & .183 & .320 & .170 \\
\hline Residual variance & $47.151^{*}$ & 1.134 & $52.716^{*}$ & 1.261 & $35.814^{*}$ & .895 & $38.963^{*}$ & .933 \\
\hline \multicolumn{9}{|c|}{ Model 2} \\
\hline \multicolumn{9}{|l|}{ Fixed effects } \\
\hline Intercept $\gamma_{00}$ & $49.363^{*}$ & .383 & $49.617^{*}$ & .279 & $51.613^{*}$ & .368 & $55.026^{*}$ & .725 \\
\hline Time $\gamma_{10}$ & $-.156^{*}$ & .044 & $-.186^{*}$ & .046 & $.275^{*}$ & .044 & .087 & .039 \\
\hline $\operatorname{Time}^{2} \gamma_{20}$ & -.004 & .004 & .003 & .004 & .007 & .003 & .002 & .004 \\
\hline Age $\gamma_{01}$ & $.134^{*}$ & .032 & .037 & .024 & -.005 & .029 & $-.285^{*}$ & .083 \\
\hline BASE $\gamma_{02}$ & - & - & - & - & $3.928^{*}$ & .913 & - & - \\
\hline BASE-II $\gamma_{03}$ & - & - & - & - & - & - & $3.238^{\mathrm{b}}$ & 1.325 \\
\hline Age $\times$ Time $\gamma_{11}$ & $.025^{*}$ & .005 & $.019^{*}$ & .006 & $.017^{*}$ & .006 & $-.015^{*}$ & .005 \\
\hline \multicolumn{9}{|l|}{ Cohort } \\
\hline Year of Birth $\gamma_{04}$ & $.164^{*}$ & .023 & $.041^{\mathrm{a}}$ & .019 & $-.210^{*}$ & .026 & $-.495^{*}$ & .071 \\
\hline Year of Birth $\times$ Time $\gamma_{12}$ & $.025^{*}$ & .005 & $.020^{*}$ & .005 & $-.021^{*}$ & .005 & $-.015^{*}$ & .005 \\
\hline Year of Birth $\times$ Age $\gamma_{05}$ & $-.003^{*}$ & .001 & - & - & $-.006^{*}$ & .001 & - & - \\
\hline Year of Birth $\times$ Age $\times$ Time & - & - & - & - & $-.001^{*}$ & .000 & - & - \\
\hline \multicolumn{9}{|l|}{$\begin{array}{l}\gamma_{13} \\
\text { Random effects }\end{array}$} \\
\hline Var. intercept & $47.936^{*}$ & 1.988 & $47.401^{*}$ & 2.025 & $40.296^{*}$ & 1.675 & $44.388^{*}$ & 1.773 \\
\hline Var. time & $.056^{*}$ & .019 & .031 & .019 & $.044^{*}$ & .015 & .026 & .014 \\
\hline Cov. intercept, time & .425 & .187 & .231 & .180 & .331 & .143 & .174 & .151 \\
\hline \multicolumn{9}{|l|}{ Variance explained } \\
\hline In intercept & \multirow{2}{*}{\multicolumn{2}{|c|}{$\begin{array}{l}.035 \\
.008\end{array}$}} & \multirow{2}{*}{\multicolumn{2}{|c|}{$\begin{array}{l}.001 \\
.023\end{array}$}} & \multirow{2}{*}{\multicolumn{2}{|c|}{$\begin{array}{l}.338 \\
.668\end{array}$}} & \multicolumn{2}{|c|}{$\begin{array}{l}.243 \\
047\end{array}$} \\
\hline In time & & & & & & & & \\
\hline Residual variance & $46.913^{*}$ & 1.128 & $52.531^{*}$ & 1.255 & $35.405^{*}$ & .875 & $38.792^{*}$ & .925 \\
\hline
\end{tabular}

Note. $\quad N=2,450$ who provided 6,663 observations. BASE $=$ participants' study of origin was the Berlin Aging Study, BASE-II = participants' study of origin was the Berlin Aging Study II. Unstandardized estimates and SEs presented. Control belief ratings were $T$-standardized using baseline data of the entire sample $(M=50, S D=10)$. Age represents the median of all observations per participants and was centered at age 70 years. Year of birth centered at 1925.

${ }^{\mathrm{a}} p=.034 .{ }^{\mathrm{b}} p=.015$.

${ }^{*} p<.01$.

Later birth year was also associated with the age gradient for internal control beliefs over desirable outcomes $\left(\gamma_{05}=-0.003\right.$, $p=.004)$. In the left panel of Figure 2, the longer trend lines show that older individuals in the earlier-born cohort generally reported higher internal control beliefs over desirable outcomes (long trend line for the dashed group is increasing), a positive age (selection) gradient, and that the gradient was less steep for the later-born cohorts (long trend lines for the solid black and gray groups are shallower). ${ }^{2}$ As a consequence, cohort differences in internal control beliefs over desirable outcomes are a bit weaker in older ages. In contrast, internal control beliefs over undesirable outcomes did not show any cohort differences in the age-gradients, and for that matter the long trend lines in the right panel are all relatively parallel and flat across age.

As seen in the right side of Table 3 , later birth year was also associated with lower levels of external control beliefs in both powerful others $\left(\gamma_{04}=-0.210, p<.001\right)$ and chance $\left(\gamma_{04}=-0.495, p<.001\right)$ at age 70 , less pronounced intraindividual increases in external control beliefs in powerful others $\left(\gamma_{12}=-0.021, p<.001\right)$, and a bit more decline in external control beliefs in chance $\left(\gamma_{12}=-0.015, p<.001\right)$. These cohort differences are depicted in Figure 3. In both panels, the earlier-

\footnotetext{
${ }^{2}$ We note that age convergence in the sample would be evident if the 5 -year trajectories fit well to one continuous trajectory over all ages. However, nonconvergence of 5-year age differences and 5-year intraindividual changes is readily discernible by the mainly nonoverlapping trajectories. This reflects the well-established findings in long-term longitudinal studies that when, for example, 60 -year olds in a given study age 5 years, they will not necessarily develop into those who started participating in the study as 65-year olds. For broader discussion of the theme, see Sliwinski, Hoffman, and Hofer (2010).
} 

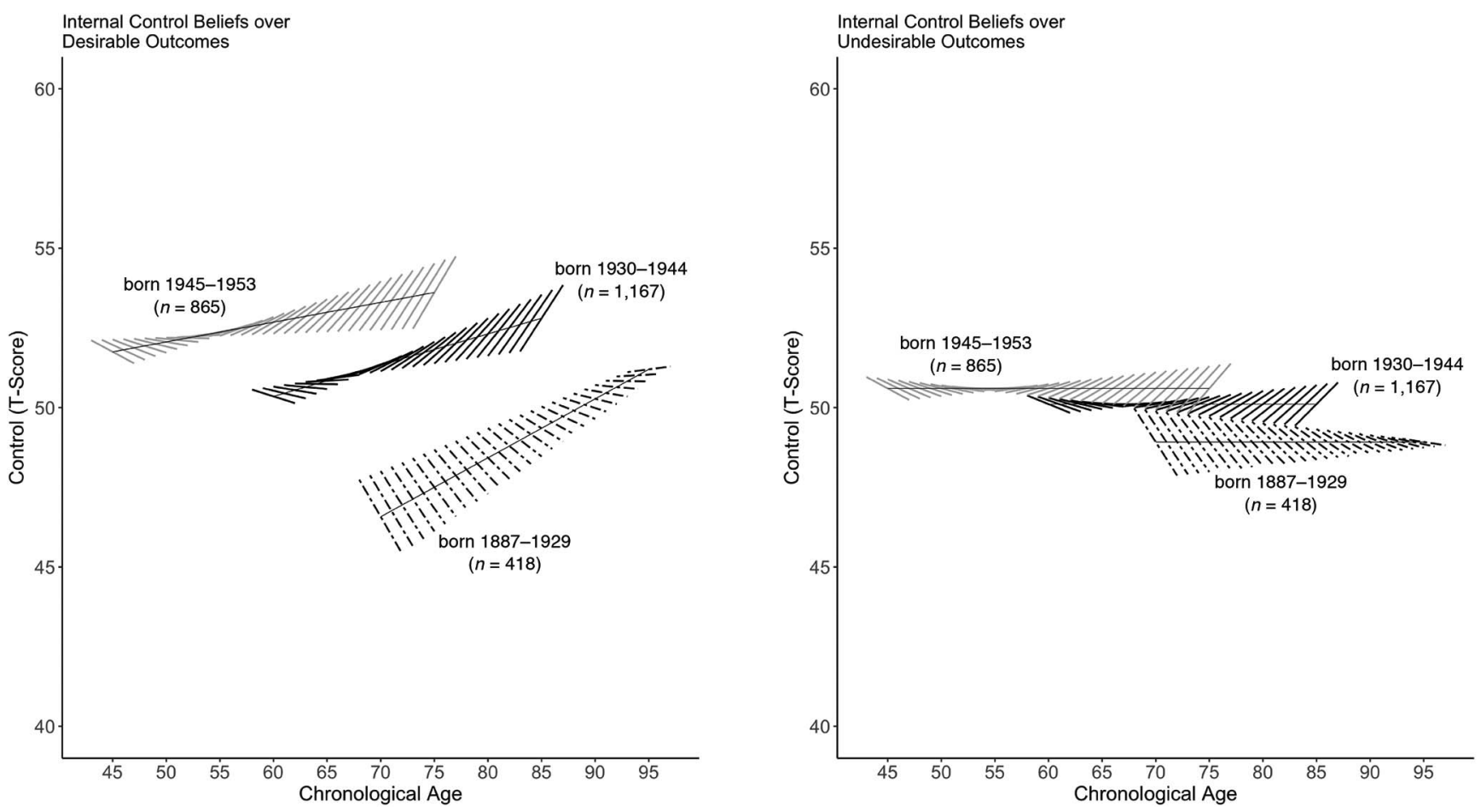

Figure 2. Cohort differences in model-implied trajectories of internal control beliefs over desirable outcomes (left panel) and over undesirable outcomes (right panel). For each cohort, the figure shows model-implied within-person changes over 5 years in $25+$ age bins of 1-year age increments as short, thick lines. The single linear age and selection trend for each cohort is shown as long, thin line. The earlier-born cohort (dashed lines) exhibited in old age within-person declines on both dimensions of internal control beliefs, whereas later-born cohorts (solid black and gray lines) reported in part considerably more internal control beliefs and exhibited within-person stability across old age. If anything, later-born cohorts exhibited in old age within-person increases in internal control beliefs.

born cohort (dashed lines) exhibited intraindividual increases in external control beliefs (short dashed lines mostly pointing upward), whereas later-born cohorts (solid black and gray lines) reported lower levels of external control beliefs that were maintained or declined over time-in-study (short solid black and gray lines mostly pointing downward).

Later birth year was also associated with the age gradient for external control beliefs in powerful others $\left(\gamma_{05}=-0.006, p<\right.$ $.001)$ and age-related differences in intraindividual change $\left(\gamma_{13}=-0.001, p<.001\right)$. Visually, the longer trend lines in the left panel of Figure 3 show that older individuals in the earlierborn cohort generally reported higher external control beliefs in powerful others (long trend line for the dashed group is increasing), a positive age (selection) gradient. In contrast, older individuals in the later-born cohorts generally reported lower external control beliefs in powerful others (long trend lines for the solid black and gray groups are decreasing). As a consequence, cohort differences in external control beliefs in powerful others are a bit stronger in older ages.

Effect sizes were quantified as the reduction in unexplained variance in the trajectory features (in intercepts and rates of change; Snijders \& Bosker, 1999) relative to a model that did not include the person-level predictors (Model 1). Age and birth year (and study of origin) together accounted for variance that amounted to small effect sizes for the two dimensions of internal control beliefs (between 0.1 and 3.5\%) and moderate to large effect sizes for the two dimensions of external control beliefs (between 4.7 and 66.8\%).

\section{The Role of Socio-Demographic, Physical Health, Cognitive, and Social Factors}

Results from models where sociodemographic, physical health, cognitive, and social factors were added as additional individuallevel predictors of control beliefs are shown in Table 4. Being a woman (in the earlier-born cohort) was associated with lower levels on both dimensions of internal control (e.g., desirable outcomes: $\left.\gamma_{04}=-1.408, p=.001\right)$ and higher levels on both dimensions of external control (e.g., chance: $\gamma_{04}=2.335, p<$ .001). Being more educated was associated with lower level $\left(\gamma_{05}=-1.026, p<.001\right)$ and intraindividual decline $\left(\gamma_{13}=-0.053, p=.006\right)$ of external control beliefs in chance. Being more educated was also associated with lower levels of internal control beliefs over desirable outcomes $\left(\gamma_{05}=-0.642\right.$, $p=.001$ ), but this association was moderated by birth year $\left(\gamma_{012}=0.044, p<.001\right)$. Better performance on the Digit Symbol test was associated with lower levels on both dimensions of external control (e.g., chance: $\gamma_{08}=-0.043, p<.001$ ) and 

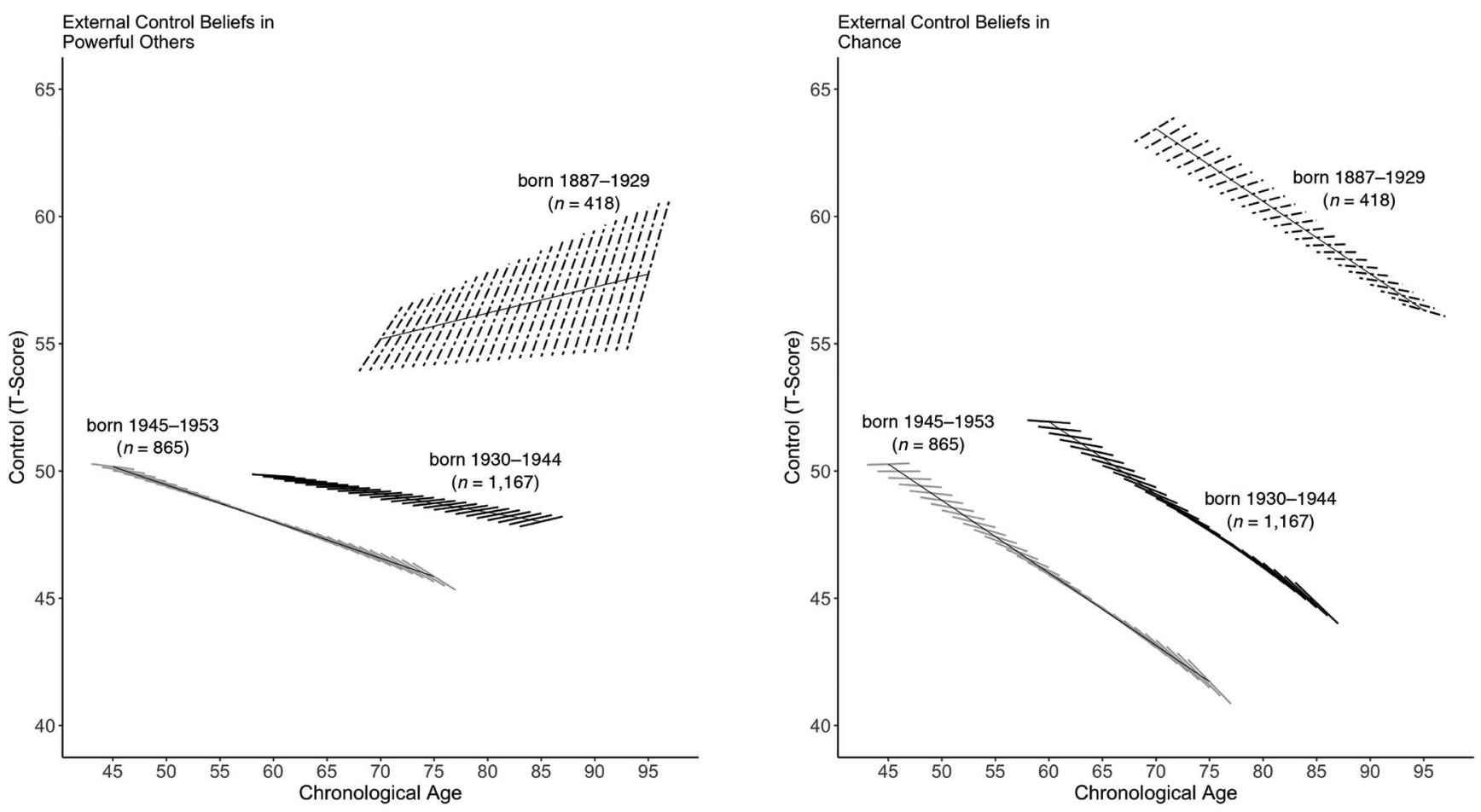

Figure 3. Cohort differences in model-implied trajectories of external control beliefs in powerful others (left panel) and in chance (right panel). For each cohort, the figure shows model-implied within-person changes over 5 years in $25+$ age bins of 1-year age increments as short, thick lines. The single linear age and selection trend for each cohort is shown as long, thin line. The earlier-born cohort (dashed lines) exhibited in old age within-person increases on both external control dimensions (particularly steep on powerful others), whereas later-born cohorts (solid black and gray lines) reported considerably lower external control beliefs and exhibited within-person stability across old age. If anything, later-born cohorts exhibited in old age within-person declines in external control beliefs in chance.

slightly steeper increases in external control beliefs in chance $\left(\gamma_{16}=0.004, p=.004\right)$. Associations for year of birth were of similar size to those reported in Table 3 (e.g., level effect on internal control beliefs over desirable outcomes: $\gamma_{04}=0.164, p<$ .001 in Table 3 and $\gamma_{010}=0.153, p<.001$ in Table 4). Additional interaction effects with birth year emerged, a birth cohort by gender interaction on external control beliefs in powerful others $\left(\gamma_{013}=-0.087, p<.001\right)$ and a birth cohort by Digit Symbol test interaction on external control beliefs in powerful others $\left(\gamma_{014}=\right.$ $0.002, p=.002)$. The three interaction effects are graphically illustrated in Figure 4. The graphs show that among earlier-born participants (dashed lines), pronounced differences existed between higher versus lower cohort-normed education groups on internal control beliefs over desirable outcomes (left Panel a), between men and women on external control beliefs in powerful others (middle Panel b), and between higher versus lower cognitive functioning groups on external control beliefs in powerful others (right Panel c). In contrast, these differences were considerably smaller among later-born cohorts (solid black and gray lines).

The sociodemographic, physical health, cognitive, and social factors explained additional variance in all four dimensions of control beliefs. Comparing the proportion of variance explained (shown in bottom rows of Table 4) with prior models that did not include these predictors (bottom rows of Table 3) indicates that individual differences in gender, education, grip strength, digit symbol performance, and marital history conjointly accounted for additional variance in both levels of control beliefs at age 70 (5.0 and $5.3 \%$ of variance in individuals' level of internal control beliefs over desirable and undesirable outcomes, respectively; 35.5 and $31.4 \%$ in levels of external control beliefs in powerful others and chance, respectively) and intraindividual rates of change in control beliefs ( 7.2 and $24.5 \%$ for internal control beliefs over desirable and undesirable outcomes, respectively; 67.5 and $24.1 \%$ for external control beliefs in powerful others and chance, respectively).

Of particular interest was also how much of the variance accounted for by birth year in the prior model was now accounted for by these potentially explanatory factors. Comparison of residual variances in intercepts and slopes across models with subsets of the predictors (e.g., explanatory factors only vs. birth year only) revealed that the explanatory factors accounted for $37.6 \%$ of the cohort-related differences in level for external control beliefs in powerful others, and for $22.9 \%$ of the cohort-related differences in rates of intraindividual change. Similarly, the explanatory factors accounted for $44.2 \%$ of the cohort-related differences in level of internal control beliefs over desirable outcomes. Cohort-related differences in levels and rates of change in the other dimensions of 
Table 4

Growth Models of Control Beliefs: The Role of Age, Year of Birth, and the Correlates

\begin{tabular}{|c|c|c|c|c|c|c|c|c|}
\hline \multirow[b]{3}{*}{ Parameter } & \multicolumn{4}{|c|}{ Internal control beliefs over } & \multicolumn{4}{|c|}{ External control beliefs in } \\
\hline & \multicolumn{2}{|c|}{ Desirable outcomes } & \multicolumn{2}{|c|}{$\begin{array}{l}\text { Undesirable } \\
\text { outcomes }\end{array}$} & \multicolumn{2}{|c|}{ Powerful others } & \multicolumn{2}{|c|}{ Chance } \\
\hline & Est. & $S E$ & Est. & $S E$ & Est. & $S E$ & Est. & $S E$ \\
\hline \multicolumn{9}{|l|}{ Fixed effects } \\
\hline Intercept $\gamma_{00}$ & $48.637^{*}$ & .309 & $49.471^{*}$ & .300 & $51.473^{*}$ & .380 & $53.605^{*}$ & .757 \\
\hline Time $\gamma_{10}$ & $-.172^{*}$ & .046 & $-.202^{*}$ & .047 & $.277^{*}$ & .046 & .086 & .040 \\
\hline Time $^{2} \gamma_{20}$ & -.003 & .004 & .004 & .004 & .008 & .003 & .002 & .004 \\
\hline Age $\gamma_{01}$ & $.078^{*}$ & .026 & .044 & .026 & -.071 & .032 & -.178 & .082 \\
\hline BASE $\gamma_{02}$ & - & - & - & - & $2.947^{*}$ & .941 & - & - \\
\hline BASE-II $\gamma_{03}$ & - & - & - & - & - & - & 1.033 & 1.342 \\
\hline Age $\times$ Time $\gamma_{11}$ & $.024^{*}$ & .006 & $.020^{*}$ & .006 & .014 & .006 & $-.013^{*}$ & .005 \\
\hline \multicolumn{9}{|l|}{ Correlates } \\
\hline Women $\gamma_{04}$ & $-1.408^{*}$ & .428 & $-3.095^{*}$ & .428 & $1.668^{*}$ & .492 & $2.335^{*}$ & .394 \\
\hline Education $\gamma_{05}$ & $-.642^{*}$ & .198 & -.119 & .162 & .312 & .146 & $-1.026^{*}$ & .149 \\
\hline Grip strength $\gamma_{09}$ & -.003 & .012 & .001 & .012 & .006 & .011 & .024 & .011 \\
\hline Digit Symbol $\gamma_{08}$ & -.004 & .012 & -.006 & .012 & $-.085^{*}$ & .014 & $-.043^{*}$ & .012 \\
\hline Married $\gamma_{06}$ & .286 & .443 & -.111 & .441 & .635 & .406 & -.714 & .406 \\
\hline Divorced $\gamma_{07}$ & .086 & .513 & -.067 & .511 & -.016 & .464 & 1.015 & .470 \\
\hline Women $\times$ Time $\gamma_{12}$ & .024 & .048 & .024 & .048 & -.047 & .042 & -.098 & .042 \\
\hline Education $\times$ Time $\gamma_{13}$ & .030 & .022 & .028 & .022 & -.023 & .019 & $-.053^{*}$ & .019 \\
\hline Grip Strength $\times$ Time $\gamma_{17}$ & -.001 & .001 & -.001 & .001 & -.001 & .001 & .000 & .001 \\
\hline Digit Symbol $\times$ Time $\gamma_{16}$ & -.002 & .002 & .000 & .002 & -.002 & .001 & $.004^{*}$ & .001 \\
\hline Married $\times$ Time $\gamma_{14}$ & .042 & .059 & .117 & .060 & -.089 & .052 & -.021 & .052 \\
\hline Divorced $\times$ Time $\gamma_{15}$ & -.127 & .070 & -.067 & .071 & -.038 & .062 & .065 & .062 \\
\hline \multicolumn{9}{|l|}{ Cohort } \\
\hline Year of birth $\gamma_{010}$ & $.153^{*}$ & .022 & $.054^{\mathrm{a}}$ & .022 & $-.210^{*}$ & .028 & $-.359^{*}$ & .074 \\
\hline Year of Birth $\times$ Time $\gamma_{18}$ & $.026^{*}$ & .005 & $.020^{*}$ & .005 & $-.020^{*}$ & .005 & $-.016^{*}$ & .005 \\
\hline Year of Birth $\times$ Age $\gamma_{011}$ & - & - & - & - & $-.003^{*}$ & .001 & - & - \\
\hline Year of Birth $\times$ Age $\times$ Time $\gamma_{19}$ & - & - & - & - & $-.001^{*}$ & .000 & - & - \\
\hline Year of Birth $\times$ Education $\gamma_{012}$ & $.044^{*}$ & .010 & - & - & - & - & - & - \\
\hline Year of Birth $\times$ Women $\gamma_{013}$ & - & - & - & - & $-.087^{*}$ & .021 & - & - \\
\hline Year of Birth $\times$ Digit Symbol $\gamma_{014}$ & - & - & - & - & $.002^{*}$ & .001 & - & - \\
\hline \multicolumn{9}{|l|}{ Random effects } \\
\hline Var. intercept & $47.187^{*}$ & 1.965 & $44.932 *$ & 1.957 & $39.287^{*}$ & 1.638 & $40.229^{*}$ & 1.659 \\
\hline Var. time & $.052^{*}$ & .018 & .024 & .019 & $.043^{*}$ & .015 & .021 & .014 \\
\hline Cov. Intercept, time & .404 & .186 & .254 & .177 & .357 & .140 & .191 & .146 \\
\hline \multicolumn{9}{|l|}{ Variance explained } \\
\hline In intercept & \multirow{2}{*}{\multicolumn{2}{|c|}{$\begin{array}{l}.050 \\
.072\end{array}$}} & \multirow{2}{*}{\multicolumn{2}{|c|}{$\begin{array}{l}.053 \\
.245\end{array}$}} & \multirow{2}{*}{\multicolumn{2}{|c|}{$\begin{array}{r}.355 \\
675\end{array}$}} & \multicolumn{2}{|c|}{.314} \\
\hline In time & & & & & & & & \\
\hline Residual variance & $46.863^{*}$ & 1.126 & $52.605^{*}$ & 1.256 & $35.303^{*}$ & .871 & $38.864^{*}$ & .927 \\
\hline
\end{tabular}

Note. $\quad N=2,450$ who provided 6,663 observations. BASE $=$ participants' study of origin was the Berlin Aging Study; BASE-II $=$ participants' study of origin was the Berlin Aging Study II. Unstandardized estimates and standard errors are presented. Control belief ratings were $T$-standardized using baseline data of the entire sample $(M=50, S D=10)$. Age represents the median of all observations per participants and was centered at age 70 years. Year of birth centered at 1925

${ }^{\mathrm{a}} p=.013$.

$* p<.01$.

control beliefs (e.g., in levels and rates of change on internal control beliefs in undesirable outcomes and on external control beliefs in chance) were more or less entirely accounted for by the sociodemographic, physical health, cognitive, and social variables.

\section{Follow-Up Analyses}

Follow-up analyses tested for study homogeneity and robustness of findings. First, we checked for homogeneity across samples. Specifically, we identified a subgroup of participants from the younger cohort in ILSE $(n=278$ who filled out the questionnaires in 2013 to 2017 and ranged in age between 61 and 66 years) who could be equated in age and historical time to a subgroup of participants from BASE-II $(n=91$ who filled out the question- naires in 2014 to 2016 and ranged in age between 62 and 66 years). The two groups of participants, obtained from different studies of origin and location, did not differ on any of the four dimensions of control beliefs (all $p$ s $>.10$ ).

Second, we restricted the analysis to the BASE and BASE-II samples (i.e., excluding the non-Berlin-based ILSE sample). As seen in Table 1 in the online supplemental material, results largely mirror those obtained in the larger three-study sample. The noted cohort-related differences in level of internal and external control beliefs were all similar. The noted cohort-related differences in intraindividual rates of change were in some cases no longer statistically significant, but had similar parameter values (e.g., for internal control beliefs over undesirable outcomes, $\gamma_{12}=0.20$, 
a

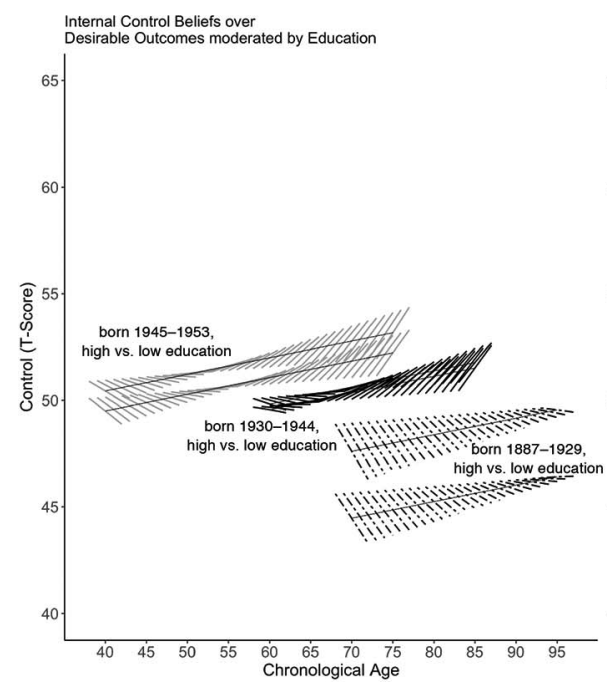

b

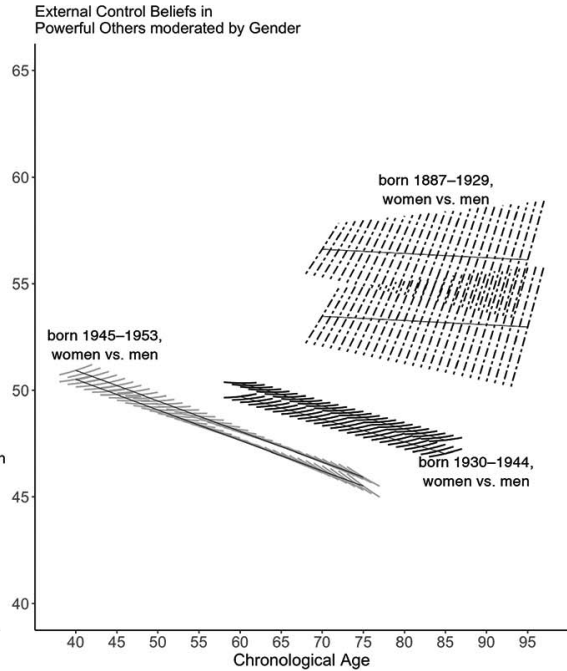

C

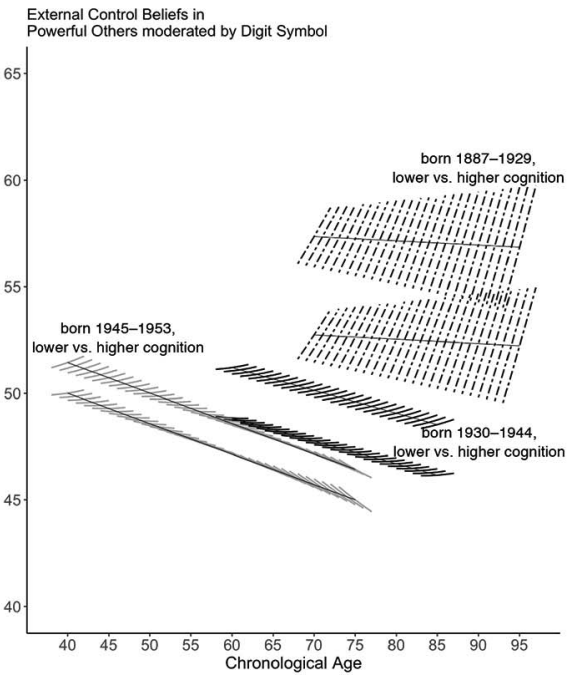

Figure 4. Cohort differences in model-implied trajectories of control beliefs. For each cohort, the figure shows model-implied within-person changes over 5 years in $25+$ age bins of 1 -year age increments as short, thick lines. The single linear age and selection trend for each cohort is shown as long, thin line. Formerly disadvantaged population segments have in part caught-up over historical time in their control beliefs, such that divides in control beliefs between population segments that had existed earlier in historical time have narrowed today. Among earlier-born participants (dashed lines), pronounced differences existed between higher versus lower cohort-normed education groups on internal control beliefs over desirable outcomes (left Panel a), between men and women on external control beliefs in powerful others (middle Panel b), and between higher versus lower cognitive functioning groups on external control beliefs in powerful others (right Panel c). In contrast, these differences were considerably smaller among later-born cohorts (solid black and gray lines).

$p<.001$ in the full sample vs. $\gamma_{12}=0.19, p=.097$ in the smaller sample). In summary, the noted cohort-related differences do not appear to be primarily driven by study-related differences in sampling.

Finally, we added a contrast-coded predictor variable indicating whether participants had been living in West Germany (BASE; ILSE participants from Heidelberg; BASE-II: answering "no" to the question whether they had lived for 1 year or longer in East Germany) or East Germany (ILSE participants from Leipzig; BASE-II: answering "yes" to the question whether they had lived for 1 year or longer in East Germany). Note that all participants born before 1930 in our study lived (in old age) in former West Germany. Results of these follow-up analyses are presented in Table 2 in the online supplemental material. Three sets of findings are of note. First, individuals who lived in East Germany versus West Germany did not differ in levels or rates of intraindividual change on any of the four dimensions of control beliefs. Second, and most important for the question under study, the substantive pattern of effects found for year of birth as reported in Table 4 holds when we additionally covary for region of living. Finally, two interaction effects between year of birth and East versus West Germany emerged. A two-way interaction indicated that the cohort differences in levels of external control beliefs in powerful others $\left(\gamma_{012}=0.107, p=.0182\right)$ were somewhat more pronounced in East Germany. In a similar vein, a three-way interaction $\left(\gamma_{110}=-0.011, p=.006\right)$ indicated that cohort differences in the rate of intraindividual change in internal control beliefs in desirable outcomes were more pronounced in East Germany.

\section{Discussion}

The current study examined whether and how historical changes widely documented for physical health and cognition generalize to later-life age trajectories of control beliefs, which serve an important role as a psychological resource for successful aging. Combining three independent studies (BASE, ILSE, and BASE-II) allowed us to examine overlapping multiyear within-person longitudinal change data from ages 61 to 85 years among cohorts born between 1905 and 1953. Results revealed that earlier-born cohorts exhibited lower levels and age-related declines on both internal control beliefs over desirable and over undesirable outcomes, whereas later-born cohorts perceived relatively higher internal control and maintained this into old age. Earlier-born cohorts also experienced higher levels and steep age-related increases on both external control beliefs in powerful others and in chance, whereas later-born cohorts perceived lower external control and were relatively stable across old age. Education and gender disparities in control beliefs documented in the past have narrowed for those born more recently. We also examined the role of factors known to differ between individuals and cohorts, including sociodemographic (gender, education), physical health (grip strength), cognitive (Digit Symbol), and social factors (being married, divorced). Inclusion of these variables in the models increased the amount of variance explained and accounted for sizable portions of the cohort effects observed. We discuss potential underlying mechanisms and consider conceptual and societal implications of our findings. 


\section{Historical Changes in Age Trajectories of Internal and External Control Beliefs}

The current study extends earlier reports from BASE and BASE-II (Hülür et al., 2016) by making use of within-person longitudinal change data (rather than cross-sectional data only), examining the full samples (rather than a small selection of subsamples), and extending the data with an independent and complementary third study that is well-established in the adult development and aging literature (i.e., ILSE data as used in, e.g., Allemand, Zimprich, \& Hertzog, 2007; Braun, Schmukle, \& Kunzmann, 2017; Siebert, Wahl, \& Schröder, 2016).

Our findings of cohort differences in both levels and rates of change in multiple distinct dimensions of control beliefs showcase the plasticity of individual development in key psychosocial variables (Lindenberger, 2018). Plasticity was preserved into the oldest ages studied here, as exemplified by historical change in external control beliefs in powerful others being particularly pronounced in older ages. This suggests that what has been observed among certain generations of older adults (e.g., control beliefs examined in the 1990s and 2000s: Gerstorf, Ram, Lindenberger, \& Smith, 2013; Lachman \& Weaver, 1998b; Mirowsky \& Ross, 2007) may not necessarily generalize to later-born cohorts, but may be subject to in part substantial historical change in perceived internal and external opportunities and constraints to exert control.

One interpretation of internal control beliefs over undesirable outcomes is that these are not adaptive and self-protective because feelings of guilt may arise when people attribute failure experience to one's own lack of capacity or diligence as opposed to bad circumstances, other people's (wrong)doings, or bad luck (Lang \& Heckhausen, 2001). Another interpretation is that such internal control beliefs may be adaptive because people interpret this as personal responsibility for what happens in their lives, no matter whether the outcome is desirable or undesirable. As a consequence, people may think that they should take more care in the future to avoid the bad things that have happened to them in the past or present. It is of course possible that one generation views the construct differently (e.g., earlier-born: guilt) than another generation (e.g., later-born: responsibility). It will be instructive in future research to contrast specifically tailored operational definitions of the above noted divergent interpretations and to investigate the functional and adaptive implications that arise.

More mechanism-oriented research is needed to disentangle whether older adults living today indeed experience old age as more internally controllable and less externally controlled, have more opportunities and capacities to exert control over their lives, are confronted with fewer barriers, or are in a position to overcome these barriers more easily or more consistently, particularly in times of strain (Ross \& Mirowsky, 2013). Notably, historical changes in control beliefs may not necessarily reflect changes in life circumstances and adaptation to historically changing developmental ecologies, but simply a more effective choice of goals that are within reach while the constraints older adults are confronted with have remained unchanged. To illustrate, it is possible that later-born generations have become better at self-regulating by, for example, more easily letting go of blocked goals and thereby increasingly de-couple objective loss of resources from subjective control perceptions. Selecting goals that are attainable accommodates the objective loss of personal control capacity people may experience, allows disengagement from unobtainable goals, and puts the individual in a position to focus on outcomes that are internally controllable and not as much subject to the constraints by powerful others and chance. With the current data, it has not been possible to test such speculation.

\section{The Role of Socio-Demographic, Physical Health, Cognitive, and Social Factors}

Our results for the correlates square well with earlier reports about the role of sociodemographic, physical health, cognitive, and social factors for perceptions of control (Drewelies, Deeg, et al., 2018; Mirowsky \& Ross, 2007; Shockley \& Shen, 2015). For example, women, people with lower education, and people who are cognitively less fit are each experiencing less favorable age trajectories on perceptions of control. In the full models though, our functional health index (grip strength) was not uniquely associated with age trajectories of control beliefs. Over and above the select nature of the samples, this was in part because of the range of variables examined as predictors. In follow-up, zero-order analyses, lower grip strength exhibited the expected associations with lower internal control beliefs and higher external control beliefs.

Most important for our research questions, our findings indicate that the individual and cohort difference factors included were indeed highly relevant because the variables accounted for sizable portions of the cohort effects observed for control beliefs. These results are consistent with the idea that dimensions of control beliefs are shaped by and to a considerable degree reflect resources, adaptation processes, and life circumstances in other key areas of functioning (Antonucci, 2001; Lachman, 2006) that are known to evince historical changes, including functional and cognitive health. Based on earlier research (Infurna \& Mayer, 2015), we had expected that physical health factors would be particularly important for (cohort differences in) external control beliefs. However, with the exception of cognition, which was associated with external control beliefs, no other correlate showed dimension-specific patterns of associations with cohort differences. Viewed as a whole, the results support the notion that there are some manifold dynamics that link control beliefs with functioning and development in key areas of life. As such, societal optimizations in any one area are likely to also impact other areas.

Gaps in control beliefs between more- and less disadvantaged population segments (including people with lower education and women) appear to have narrowed over historical time. This is in line with earlier cross-sectional time-lag analyses in the United States (Drewelies, Agrigoroaei, et al., 2018) and extends this finding to longitudinal age trajectories. More and better-quality education as well as reductions in gender inequalities in education and labor force participation may have particularly changed the living conditions or the resources available to exert control over and shape one's own life for those at the lower end of the SES spectrum and for older women. Similarly, older adults' everyday life in current times in Germany, relative to earlier times, is less shaped by pervasive historical events such as economic crises and Cold War politics. It is an open question what role processes of differential population (survival) selection play and how our findings generalize to the impact of historical events and change in other countries. 
Our findings do not support inferences about the functional and adaptive utility of the cohort effects observed. Perceiving oneself in charge of what happens in one's life often helps people make the most out of one's resources and exploit existing windows of opportunity. Similarly, believing that it is not chance, fate, or luck or the behavior of other people that determine major outcomes in one's own life presumably puts older adults in a position to maintain remaining resources as long as possible. However, such beliefs and the resulting action tendencies (tenacious goal pursuit) and social signals (assertiveness) may come with costs when life conditions change. For example, when people have no or very little control over stressors, failure experiences become increasingly likely and believing in external forces such as powerful others or chance become more beneficial (M. M. Baltes, 1996). Thus, it would be highly informative to systematically examine when and how the cohort differences observed for age trajectories of control beliefs are accompanied by and potentially contribute to corresponding cohort differences in measures of well-being and quality of life.

\section{Study Limitations and Outlook}

In closing, we note limitations of our study design, measures, and samples. To begin with, our study design did not allow disentangling year-of-birth effects from those of study location (e.g., big city such as Berlin [with differences between East and West] vs. midsize cities such as Leipzig [located in former East Germany] and Heidelberg [located in former West Germany]) and test year (period effect). To alleviate concerns, we conducted three sets of follow-up analyses. Although findings obtained bolster our main conclusions, we caution against overinterpreting these follow-up results. For example, we were not in a good position to test East versus West differences because for a given age range participants either came from East Germany or from West Germany (e.g., we have no East Germans older than age 70 in the early 1990s in our sample), but not from both German states similarly often. Furthermore, some members of the older cohorts may have moved from East to West at some point in their lives. It would be interesting to examine these and other residential location and geographic mobility differences in future studies. It is also an open question whether the cohort differences observed have unfolded early in life or later in the lives of the older generations examined here (e.g., during and after the Cold War and German Reunification) and whether these differences are a pervasive phenomenon or restricted to the years of testing.

As limitations in study measures, the limited overlap of data obtained in identical ways in all three studies restricted our choice of predictors. For example, we would expect that if we had the information available, religiosity would have contributed to cohort differences observed for external control beliefs in chance (Fiori, Brown, Cortina, \& Antonucci, 2006). Also, the control belief scales had in part low to moderate reliabilities. Consistent with the long tradition of theoretical work demonstrating that the four dimensions are distinct from one another (Krampen, 1981; Kunzmann et al., 2002; Levenson, 1981; Rotter, 1966; Smith \& Baltes, 1999), we nevertheless decided against pooling items and thereby increase Cronbach's $\alpha$ because considering the scales separately revealed insights into in part different historical changes and differential associations of historical changes with the correlates.
For example, level differences at age 70 years between cohorts were sizable for beliefs in powerful others, but doubled in size for beliefs in chance.

Notably, the scale composition across dimensions was not fully balanced. Distinguishing between desirable and undesirable outcomes was possible for internal control beliefs, but not for external control beliefs in chance, and items assessing external control beliefs in powerful others only tapped into desirable outcomes. Thus, it is an open question, for example, whether and how historical changes have occurred in external control beliefs in powerful others when undesirable outcomes are considered. Because age-related declines in resources may make it adaptive to attribute failure experiences to external sources (Heckhausen et al., 2019), historical declines are probably less pronounced for beliefs that powerful others are responsible for undesirable outcomes relative to desirable outcomes as examined in our study. Future studies might also examine cohort differences in domain-specific control beliefs (Lachman \& Weaver, 1998b).

As limitations in study samples, we refer to earlier work on the two Berlin-based BASE samples who represent positive selections of the larger populations from which they were drawn (Gerstorf et al., 2015). Although the amount of selection was comparable across samples, the positive selection considerably restricts the generalizability of our findings to less positively select and more diverse populations (Clarke \& Smith, 2011). Future studies should thoroughly test whether socioeconomically deprived population segments or those in poor physical health have experienced historical changes that are comparable in direction and size with those observed here. We also note that combining the studies only allowed us to examine overlapping longitudinal change data between ages 61 and 85 years. It is an open question if our findings generalize to the period of life when current generations of 75-year olds will reach very old age and the end of life. Drawing from conceptual considerations (Lindenberger, 2014) and empirical reports using other outcome variables (Hülür, Infurna, Ram, \& Gerstorf, 2013, Hülür, Ram, \& Gerstorf, 2015), we would expect that the sizable cohort differences seen here do not carry into the last years of life and are minimized if not nullified.

\section{Conclusions and Summary}

In the current study, we have made use of data obtained independently in three studies conducted over the past almost 30 years. Combining the data allowed us to use within-person overlapping change information to examine historical changes in four dimensions of control beliefs from age 61 to 85 years. Results from a series of growth models revealed that cohorts of older adults born later in historical time evince higher levels of and less pronounced declines in internal control beliefs as well as lower levels of and less pronounced increases in external control beliefs. Previously existing gaps in control beliefs between advantaged and disadvantaged population segments are narrowing today, and sociodemographic, physical health, cognitive, and social factors were found to contribute substantially to the cohort differences observed. The exact processes and pathways by which historical changes in control beliefs operate are not yet well understood and need to be targeted in future, more mechanism-oriented research. 


\section{References}

Allemand, M., Zimprich, D., \& Hertzog, C. (2007). Cross-sectional age differences and longitudinal age changes of personality in middle adulthood and old age. Journal of Personality, 75, 323-358. http://dx.doi.org/ 10.1111/j.1467-6494.2006.00441.x

Antonucci, T. C. (2001). Social relations: An examination of social networks, social support, and sense of control. In J. E. Birren \& K. W. Schaie (Eds.), Handbook of the psychology of aging (5th ed., pp. 427-453). San Diego, CA: Academic Press.

Baltes, M. M. (1996). The many faces of dependency in old age. New York, NY: Cambridge University Press.

Baltes, P. B., \& Baltes, M. M. (1986). The psychology of control and aging. Hillsdale, NJ: Erlbaum.

Baltes, P. B., Lindenberger, U., \& Staudinger, U. M. (2006). Life span theory in developmental psychology. In W. Damon \& R. M. Lerner (Eds.), Handbook of child psychology: Volume 1. Theoretical models of human development (6th ed., pp. 569-664). New York, NY: Wiley.

Baltes, P. B., \& Mayer, K. U. (Eds.). (1999). The Berlin Aging Study: Aging from 70 to 100. New York, NY: Cambridge University Press.

Bauernschuster, S., \& Falck, O. (2015). Spatial diffusion of ideas and their long-lasting imprints-Evidence from Froebel's kindergarten movement. Journal of Economic Geography, 15, 601-630. http://dx.doi.org/ $10.1093 / \mathrm{jeg} / \mathrm{lbu} 028$

Bell, A., \& Jones, K. (2015). Age, period and cohort processes in longitudinal and life course analysis: A multilevel perspective. In C. BurtonJeangros, S. Cullati, A. Sacker, \& D. Blane (Eds.), A life course perspective on health trajectories and transitions: Life course research and social policies (Vol. 4, pp. 197-213). San Heidelberg, Germany: Springer. http://dx.doi.org/10.1007/978-3-319-20484-0_10

Bertram, L., Böckenhoff, A., Demuth, I., Düzel, S., Eckardt, R., Li, S.-C., . . Steinhagen-Thiessen, E. (2014). Cohort profile: The Berlin Aging Study II (BASE-II). International Journal of Epidemiology, 43, 703712. http://dx.doi.org/10.1093/ije/dyt018

Boyle, G. J. (1991). Does item homogeneity indicate internal consistency or item redundancy in psychometric scales? Personality and Individual Differences, 12, 291-294. http://dx.doi.org/10.1016/0191-8869(91) 90115-R

Brandtstädter, J. (1989). Personal self-regulation of development: Crosssequential analyses of development-related control beliefs and emotions. Developmental Psychology, 25, 96-108. http://dx.doi.org/10.1037/ 0012-1649.25.1.96

Brandtstädter, J., \& Rothermund, K. (1994). Self-percepts of control in middle and later adulthood: Buffering losses by rescaling goals. Psychology and Aging, 9, 265-273. http://dx.doi.org/10.1037/0882-7974.9 .2 .265

Brandtstädter, J., \& Rothermund, K. (2002). The life-course dynamics of goal pursuit and goal adjustment: A two process framework. Developmental Review, 22, 117-150. http://dx.doi.org/10.1006/drev.2001.0539

Braun, T., Schmukle, S. C., \& Kunzmann, U. (2017). Stability and change in subjective well-being: The role of performance-based and self-rated cognition. Psychology and Aging, 32, 105-117. http://dx.doi.org/10 .1037/pag0000153

Bronfenbrenner, U. (1986). Ecology of the family as a context for human development research perspectives. Developmental Psychology, 22, 723-742. http://dx.doi.org/10.1037/0012-1649.22.6.723

Caplan, L. J., \& Schooler, C. (2003). The roles of fatalism, self-confidence, and intellectual resources in the disablement process in older adults. Psychology and Aging, 18, 551-561. http://dx.doi.org/10.1037/08827974.18.3.551

Cherlin, A. (2010). Demographic trends in the United States: A review of research in the 2000s. Journal of Marriage and Family, 72, 403-419. http://dx.doi.org/10.1111/j.1741-3737.2010.00710.x
Cho, E., \& Kim, S. (2015). Cronbach's coefficient alpha: Well known but poorly understood. Organizational Research Methods, 18, 207-230. http://dx.doi.org/10.1177/1094428114555994

Clarke, P., \& Smith, J. (2011). Aging in a cultural context: Cross-national differences in disability and the moderating role of personal control among older adults in the United States and England. The Journals of Gerontology: Series B, 66, 457-467. http://dx.doi.org/10.1093/geronb/ gbr054

Cohen, P., Cohen, J., Aiken, L. S., \& West, S. G. (1999). The problem of units and the circumstance for POMP. Multivariate Behavioral Research, 34, 315-346. http://dx.doi.org/10.1207/S15327906MBR3403_2

Crimmins, E. M. (2018). Older persons in the Netherlands and the United States: Similar in trends in life in good cognitive health and different in trends in life without disability/poor health. American Journal of Public Health, 108, 1582-1583. http://dx.doi.org/10.2105/AJPH.2018.304759

Deeg, D. J. H., \& Huisman, M. (2010). Cohort differences in 3-year adaptation to health problems among Dutch middle-aged, 1992-1995 and 2002-2005. European Journal of Ageing, 7, 157-165. http://dx.doi .org/10.1007/s10433-010-0157-1

Drewelies, J., Agrigoroaei, S., Lachman, M. E., \& Gerstorf, D. (2018). Age variations in cohort differences in the United States: Older adults report fewer constraints nowadays than those 18 years ago, but mastery beliefs are diminished among younger adults. Developmental Psychology, 54, 1408-1425. http://dx.doi.org/10.1037/dev0000527

Drewelies, J., Deeg, D. J. H., Huisman, M., \& Gerstorf, D. (2018) Perceived constraints in late midlife: Cohort differences in the Longitudinal Aging Study Amsterdam (LASA). Psychology and Aging, 33, 754-768. http://dx.doi.org/10.1037/pag0000276

Drewelies, J., Wagner, J., Tesch-Römer, C., Heckhausen, J., \& Gerstorf, D. (2017). Perceived control across the second half of life: The role of physical health and social integration. Psychology and Aging, 32, 76-92. http://dx.doi.org/10.1037/pag0000143

Elder, G. H., Jr. (1974). Children of the Great Depression: Social change in life experience. Chicago, IL: University of Chicago Press.

Elder, G. H., Jr., \& George, L. K. (2016). Age, cohorts, and the life course. In M. J. Shanahan, J. T. Mortimer, \& M. K. Johnson (Eds.), Handbook of the life course (pp. 59-85). New York, NY: Springer. http://dx.doi org/10.1007/978-3-319-20880-0_3

Fiori, K. L., Brown, E. E., Cortina, K. S., \& Antonucci, T. C. (2006). Locus of control as a mediator of the relationship between religiosity and life satisfaction: Age, race, and gender differences. Mental Health, Religion \& Culture, 9, 239-263. http://dx.doi.org/10.1080/13694670600615482

Flynn, J. R. (1999). Searching for justice: The discovery of IQ gains over time. American Psychologist, 54, 5-20. http://dx.doi.org/10.1037/0003066X.54.1.5

Freund, A. M., \& Baltes, P. B. (1998). Selection, optimization, and compensation as strategies of life management: Correlations with subjective indicators of successful aging. Psychology and Aging, 13, 531-543. http://dx.doi.org/10.1037/0882-7974.13.4.531

Fukuyama, F. (1999). The great disruption: Human nature and the reconstitution of social order. New York, NY: Free Press.

Gatz, M., \& Karel, M. J. (1993). Individual change in perceived control over 20 years. International Journal of Behavioral Development, 16, 305-322. http://dx.doi.org/10.1177/016502549301600211

Gerstorf, D., Bertram, L., Lindenberger, U., Pawelec, G., Demuth, I., Steinhagen-Thiessen, E., \& Wagner, G. G. (2016). The Berlin Aging Study II-An overview. Gerontology, 62, 311-315. http://dx.doi.org/10 $.1159 / 000441495$

Gerstorf, D., Hülür, G., Drewelies, J., Eibich, P., Duezel, S., Demuth, I., . . . Lindenberger, U. (2015). Secular changes in late-life cognition and well-being: Towards a long bright future with a short brisk ending? Psychology and Aging, 30, 301-310. http://dx.doi.org/10.1037/ pag0000016 
Gerstorf, D., Ram, N., Hoppmann, C., Willis, S. L., \& Schaie, K. W. (2011). Cohort differences in cognitive aging and terminal decline in the Seattle Longitudinal Study. Developmental Psychology, 47, 1026-1041. http://dx.doi.org/10.1037/a0023426

Gerstorf, D., Ram, N., Lindenberger, U., \& Smith, J. (2013). Age and time-to-death trajectories of change in indicators of cognitive, sensory, physical, health, social, and self-related functions. Developmental Psychology, 49, 1805-1821. http://dx.doi.org/10.1037/a0031340

Greenfield, P. M. (2009). Linking social change and developmental change: Shifting pathways of human development. Developmental Psychology, 45, 401-418. http://dx.doi.org/10.1037/a0014726

Grimm, K. J., Ram, N., \& Estabrook, R. (2016). Growth modeling: Structural equation and multilevel modeling approaches. New York, NY: Guilford Press.

Headey, B., Muffels, R., \& Wagner, G. G. (2010). Long-running German panel survey shows that personal and economic choices, not just genes, matter for happiness. Proceedings of the National Academy of Sciences of the United States of America, 107, 17922-17926. http://dx.doi.org/10 .1073/pnas.1008612107

Heckhausen, J., \& Baltes, P. B. (1991). Perceived controllability of expected psychological change across adulthood and old age. The Journals of Gerontology: Series B, 46, P165-P173. http://dx.doi.org/10.1093/ geronj/46.4.P165

Heckhausen, J., Wrosch, C., \& Schulz, R. (2013). A lines-of-defense model for managing health threats: A review. Gerontology, 59, 438-447. http://dx.doi.org/10.1159/000351269

Heckhausen, J., Wrosch, C., \& Schulz, R. (2019). Agency and motivation in adulthood and old age. Annual Review of Psychology, 70, 191-217. http://dx.doi.org/10.1146/annurev-psych-010418-103043

Hülür, G., Ram, N., \& Gerstorf, D. (2015). Historical improvements in well-being do not hold in late life: Studies of birth year and death-year cohorts in national samples in the U.S. and Germany. Developmental Psychology, 51, 998-1012. http://dx.doi.org/10.1037/a0039349

Hülür, G., Drewelies, J., Eibich, P., Düzel, S., Demuth, I., Ghisletta, P., . . . Gerstorf, D. (2016). Cohort differences in psychosocial function over 20 years: Current older adults feel less lonely and less dependent on external circumstances. Gerontology, 62, 354-361. http://dx.doi.org/10 $.1159 / 000438991$

Hülür, G., Infurna, F. J., Ram, N., \& Gerstorf, D. (2013). Cohorts based on decade of death: No evidence for secular trends favoring later cohorts in cognitive aging and terminal decline in the AHEAD study. Psychology and Aging, 28, 115-127. http://dx.doi.org/10.1037/a0029965

Infurna, F. J., \& Mayer, A. (2015). The effects of constraints and mastery on mental and physical health: Conceptual and methodological considerations. Psychology and Aging, 30, 432-448. http://dx.doi.org/10.1037/ a0039050

Infurna, F. J., Ram, N., \& Gerstorf, D. (2013). Level and change in perceived control predict 19-year mortality: Findings from the Americans' changing lives study. Developmental Psychology, 49, 1833-1847. http://dx.doi.org/10.1037/a0031041

Jopp, D. S., \& Schmitt, M. (2010). Dealing with negative life events: Differential effects of personal resources, coping strategies, and control beliefs. European Journal of Ageing, 7, 167-180. http://dx.doi.org/10 .1007/s10433-010-0160-6

Kohut, A., Wike, R., Horowitz, J. M., Poushter, J., Barker, C., Bell, J., \& Gross, E. M. (2011). The American-Western European Values Gap. Pew Research Center's Global Attitudes Project, November, 1-24. Retrieved from http://www.atheisten-info.at/downloads/PewResearchCenter112011 .pdf

König, M., Drewelies, J., Norman, K., Spira, D., Buchmann, N., Hülür, G., . . . Demuth, I. (2018). Historical trends in modifiable indicators of cardiovascular health and self-rated health among older adults: Cohort differences over 20 years between the Berlin Aging Study (BASE) and the Berlin Aging Study II (BASE-II). PLoS ONE, 13, e0191699. http:// dx.doi.org/10.1371/journal.pone.0191699

Krampen, G. (1981). IPC-Fragebogen zu Kontrollüberzeugungen [IPC locus of control scales]. Göttingen, Federal Republic of Germany: Hogrefe.

Krause, N. (2005). God-mediated control and psychological well-being in late life. Research on Aging, 27, 136-164. http://dx.doi.org/10.1177/ 0164027504270475

Kunzmann, U., Little, T., \& Smith, J. (2002). Perceiving control: A double-edged sword in old age. The Journals of Gerontology: Series B, 57, P484-P491. http://dx.doi.org/10.1093/geronb/57.6.P484

Lachman, M. E. (2006). Perceived control over aging-related declines: Adaptive beliefs and behaviors. Current Directions in Psychological Science, 15, 282-286. http://dx.doi.org/10.1111/j.1467-8721.2006 .00453.x

Lachman, M. E., \& Weaver, S. L. (1998a). The sense of control as a moderator of social class differences in health and well-being. Journal of Personality and Social Psychology, 74, 763-773. http://dx.doi.org/10 .1037/0022-3514.74.3.763

Lachman, M. E., \& Weaver, S. L. (1998b). Sociodemographic variations in the sense of control by domain: Findings from the MacArthur studies of midlife. Psychology and Aging, 13, 553-562. http://dx.doi.org/10.1037/ 0882-7974.13.4.553

Lang, F. R., \& Heckhausen, J. (2001). Perceived control over development and subjective well-being: Differential benefits across adulthood. Journal of Personality and Social Psychology, 81, 509-523. http://dx.doi .org/10.1037/0022-3514.81.3.509

Levenson, H. (1981). Differentiating among internality, powerful others, and chance. In H. M. Lefcourt (Ed.), Research with the locus of control construct (Vol. 1, pp. 15-63). New York, NY: Academic Press. http:// dx.doi.org/10.1016/B978-0-12-443201-7.50006-3

Lindenberger, U. (2014). Human cognitive aging: Corriger la fortune? Science, 346, 572-578. http://dx.doi.org/10.1126/science.1254403

Lindenberger, U. (2018). Plasticity beyond early development: Hypotheses and questions. In A. A. Benasich \& U. Ribary (Eds.), Emergent brain dynamics: Prebirth to adolescence (Strüngmann Forum Reports) (Vol. 25, pp. 207-223). Cambridge, MA: MIT Press.

Lindenberger, U., Smith, J., Mayer, K. U., \& Baltes, P. B. (2010). In D. B. Altersstudie (Ed.), The Berlin Aging Study (3rd ed.). Berlin, Germany: Akademie Verlag.

Littell, R. C., Milliken, G. A., Stroup, W. W., Wolfinger, R. D., \& Schabenberger, O. (2006). SAS for mixed models (2nd ed.). Cary, NC: SAS Institute.

Little, R. J. A., \& Rubin, D. B. (1987). Statistical analysis with missing data. New York, NY: Wiley.

Little, T. D., Oettingen, G., Stetsenko, A., \& Baltes, P. B. (1995). Children's action-control beliefs about school performance: How do American children compare with German and Russian children? Journal of Personality and Social Psychology, 69, 686-700. http://dx.doi.org/10 .1037/0022-3514.69.4.686

Lucas, R. E., \& Donnellan, M. B. (2011). Personality development across the life span: Longitudinal analyses with a national sample from Germany. Journal of Personality and Social Psychology, 101, 847-861. http://dx.doi.org/10.1037/a0024298

Maas, I., Borchelt, M., \& Mayer, K. U. (1999). Generational experiences of old people in Berlin. In P. B. Baltes \& K. U. Mayer (Eds.), The Berlin Aging Study: Aging from 70 to 100 (pp. 83-110). Cambridge: New York: Cambridge University Press.

Machida, S., \& Holloway, S. D. (1991). The relationship between divorced mothers' perceived control over child rearing and children's postdivorce development. Family Relations, 40, 272-278. http://dx.doi.org/ $10.2307 / 585011$ 
Mayer, K. U. (2009). New directions in life course research. Annual Review of Sociology, 35, 413-433. http://dx.doi.org/10.1146/annurev soc.34.040507.134619

McArdle, J. J. (1994). Structural factor analysis experiments with incomplete data. Multivariate Behavioral Research, 29, 409-454. http://dx .doi.org/10.1207/s15327906mbr2904_5

Mirowsky, J., \& Ross, C. E. (2007). Life course trajectories of perceived control and their relationship to education. American Journal of Sociology, 112, 1339-1382. http://dx.doi.org/10.1086/511800

Mueller, S., Wagner, J., Wagner, G. G., Ram, N., \& Gerstorf, D. (2019). How far reaches the power of personality? Personality predictors of terminal decline in well-being. Journal of Personality and Social Psychology, 116, 634-650. http://dx.doi.org/10.1037/pspp0000184

Oettingen, G., Little, T. D., Lindenberger, U., \& Baltes, P. B. (1994). Causality, agency, and control beliefs in East versus West Berlin children: A natural experiment on the role of context. Journal of Personality and Social Psychology, 66, 579-595. http://dx.doi.org/10.1037/00223514.66.3.579

Oswald, W. D., \& Fleischmann, U. M. (1995). Nürnberger-Alters-Inventar (NAI) [Nuremberg inventory of old age]. Göttingen: Hogrefe.

Pearlin, L. I., \& Schooler, C. (1978). The structure of coping. Journal of Health and Social Behavior, 19, 2-21. http://dx.doi.org/10.2307/ 2136319

Pharr, S. J., Putnam, R. D., \& Dalton, R. J. (2000). A quarter-century of declining confidence. Journal of Democracy, 11, 5-25. http://dx.doi.org/ 10.1353/jod.2000.0043

Ram, N., \& Grimm, K. (2015). Growth curve modeling and longitudinal factor analysis. In W. F. Overton \& P. C. M. Molenaar (Eds.), Handbook of child psychology and developmental science: Volume 1. Theory and method (7th ed., pp. 758-788). Hoboken, NJ: Wiley. http://dx.doi.org/ 10.1002/9781118963418.childpsy 120

Raudenbush, S. W., \& Bryk, A. S. (2002). Hierarchical linear models: Applications and data analysis methods. Thousand Oaks, CA: Sage.

Reich, J. W., \& Infurna, F. J. (Eds.). (2016). Perceived control: Theory, research, and practice in the first 50 years. New York, NY: Oxford University Press.

Ross, C. E., \& Mirowsky, J. (2013). The sense of personal control: Social structural causes and emotional consequences. In C. S. Aneshensel, J. C. Phelan, \& A. Bierman (Eds.), Handbook of the sociology of mental health. Handbooks of sociology and social research (pp. 379-402). Dordrecht, the Netherlands: Springer. http://dx.doi.org/10.1007/978-94007-4276-5_19

Rotter, J. B. (1966). Generalized expectancies for internal versus external control of reinforcement. Psychological Monographs, 80, 1-28. http:// dx.doi.org/10.1037/h0092976

Rowe, J. W., \& Kahn, R. L. (1997). Successful aging. The Gerontologist, 37, 433-440. http://dx.doi.org/10.1093/geront/37.4.433

Rubio, L., Dumitrache, C. G., \& Cordón-Pozo, E. (2018). Do past stressful life events and personal control beliefs predict subjective wellbeing in old age? Evidence from a Spanish nationwide representative sample. Ageing and Society, 38, 2519-2540. http://dx.doi.org/10.1017/ S0144686X17000691

Ryan, L. H., Smith, J., Antonucci, T. C., \& Jackson, J. S. (2012). Cohort differences in the availability of informal caregivers: Are the Boomers at risk? The Gerontologist, 52, 177-188. http://dx.doi.org/10.1093/geront/ gnr142

Ryder, N. B. (1965). The cohort as a concept in the study of social change. American Sociological Review, 30, 843-861. http://dx.doi.org/10.2307/ 2090964

Ryff, C. D., \& Singer, B. (1998). The contours of positive human health. Psychological Inquiry, 9, 1-28. http://dx.doi.org/10.1207/s15327965 pli0901_1

Salomon, J. A., Wang, H., Freeman, M. K., Vos, T., Flaxman, A. D., Lopez, A. D., \& Murray, C. J. L. (2012). Healthy life expectancy for 187 countries, 1990-2010: A systematic analysis for the Global Burden Disease Study 2010. The Lancet, 380, 2144-2162. http://dx.doi.org/10 .1016/S0140-6736(12)61690-0

Santos, H. C., Varnum, M. E. W., \& Grossmann, I. (2017). Global increases in individualism. Psychological Science, 28, 1228-1239. http://dx.doi.org/10.1177/0956797617700622

Sattler, C., Wahl, H., Schröder, J., Kruse, A., Schönknecht, P., \& Kunzmann, U. (2017). Interdisciplinary Longitudinal Study on Adult Development and Aging (ILSE). In N. Pachana (Ed.), Encyclopedia of geropsychology (pp. 1-10). New York, NY: Springer. http://dx.doi.org/10 .1007/978-981-287-082-7_238

Schaie, K. W. (1965). A general model for the study of developmental problems. Psychological Bulletin, 64, 92-107. http://dx.doi.org/10.1037/ h0022371

Schaie, K. W. (2005). Developmental influences on intelligence: The Seattle Longitudinal Study. New York, NY: Oxford University Press. http://dx.doi.org/10.1093/acprof:oso/9780195156737.001.0001

Schaie, K. W. (2008). Historical processes and patterns of cognitive aging. In S. M. Hofer \& D. F. Alwin (Eds.), Handbook of cognitive aging. Interdisciplinary perspectives (pp. 368-383). Thousand Oaks, CA: Sage. http://dx.doi.org/10.4135/9781412976589.n23

Shockley, K. M., \& Shen, W. (2015). Couple dynamics: Division of labor. In K. M. Shockley \& L. T. Eby (Eds.), The Oxford handbook of work and family (pp. 125-139). New York, NY: New York: Oxford University Press.

Siebert, J. S., Wahl, H.-W., \& Schröder, J. (2016). Role of attitude toward own aging for fluid and crystallized functioning: 12 -year evidence from the ILSE study. The Journals of Gerontology: Series B, 73, 836-845. http://dx.doi.org/10.1093/geronb/gbw050

Singer, J. D., \& Willett, J. B. (2003). Applied longitudinal data analysis: Modeling change and event occurrence. New York, NY: Oxford University Press. http://dx.doi.org/10.1093/acprof:oso/9780195152968.001 .0001

Skinner, E. A. (1996). A guide to constructs of control. Journal of Personality and Social Psychology, 71, 549-570. http://dx.doi.org/10.1037/ 0022-3514.71.3.549

Sliwinski, M., Hoffman, L., \& Hofer, S. M. (2010). Evaluating convergence of within-person change and between-person age differences in age-heterogeneous longitudinal studies. Research in Human Development, 7, 45-60. http://dx.doi.org/10.1080/15427600903578169

Smith, J., \& Baltes, P. B. (1999). Trends and profiles of psychological functioning in very old age. In P. B. Baltes \& K. U. Mayer (Eds.), The Berlin Aging Study: Aging from 70 to 100 (pp. 197-226). New York, NY: Cambridge University Press.

Snijders, T. A. B., \& Bosker, R. J. (1999). Multilevel analysis: An introduction to basic and advanced multilevel modeling. London, England: Sage.

Sutin, A. R., Terracciano, A., Milaneschi, Y., An, Y., Ferrucci, L., \& Zonderman, A. B. (2013). The effect of birth cohort on well-being: The legacy of economic hard times. Psychological Science, 24, 379-385. http://dx.doi.org/10.1177/0956797612459658

Trahan, L. H., Stuebing, K. K., Fletcher, J. M., \& Hiscock, M. (2014). The Flynn effect: A meta-analysis. Psychological Bulletin, 140, 1332-1360. http://dx.doi.org/10.1037/a0037173

Twenge, J. M., \& Campbell, W. K. (2010). Birth cohort differences in the monitoring the future dataset and elsewhere: Further evidence for generation me-commentary on Trzesniewski \& Donnellan (2010). Perspectives on Psychological Science, 5, 81-88. http://dx.doi.org/10.1177/ 1745691609357015

Twenge, J. M., Zhang, L., \& Im, C. (2004). It's beyond my control: A cross-temporal meta-analysis of increasing externality in locus of control, 1960-2002. Personality and Social Psychology Review, 8, 308319. http://dx.doi.org/10.1207/s15327957pspr0803_5 
van Tilburg, T. G., Aartsen, M. J., \& van der Pas, S. (2015). Loneliness after divorce: A cohort comparison among Dutch young-old adults. European Sociological Review, 31, 243-252. http://dx.doi.org/10.1093/ esr/jcu086

Wallston, K. A., Wallston, B. S., \& DeVellis, R. (1978). Development of the Multidimensional Health Locus of Control (MHLC) Scales. Health Education Monographs, 6, 160-170. http://dx.doi.org/10.1177/ 109019817800600107
Wechsler, D. (1955). Manual for the Wechsler Adult Intelligence Scale. New York, NY: Psychological Corporation.

Received September 18, 2018

Revision received July 24, 2019

Accepted July 24, 2019

\section{Members of Underrepresented Groups: Reviewers for Journal Manuscripts Wanted}

If you are interested in reviewing manuscripts for APA journals, the APA Publications and Communications Board would like to invite your participation. Manuscript reviewers are vital to the publications process. As a reviewer, you would gain valuable experience in publishing. The P\&C Board is particularly interested in encouraging members of underrepresented groups to participate more in this process.

If you are interested in reviewing manuscripts, please write APA Journals at Reviewers@apa.org. Please note the following important points:

- To be selected as a reviewer, you must have published articles in peer-reviewed journals. The experience of publishing provides a reviewer with the basis for preparing a thorough, objective review.

- To be selected, it is critical to be a regular reader of the five to six empirical journals that are most central to the area or journal for which you would like to review. Current knowledge of recently published research provides a reviewer with the knowledge base to evaluate a new submission within the context of existing research.

- To select the appropriate reviewers for each manuscript, the editor needs detailed information. Please include with your letter your vita. In the letter, please identify which APA journal(s) you are interested in, and describe your area of expertise. Be as specific as possible. For example, "social psychology" is not sufficient-you would need to specify "social cognition" or "attitude change" as well.

- Reviewing a manuscript takes time (1-4 hours per manuscript reviewed). If you are selected to review a manuscript, be prepared to invest the necessary time to evaluate the manuscript thoroughly.

APA now has an online video course that provides guidance in reviewing manuscripts. To learn more about the course and to access the video, visit http://www.apa.org/pubs/journals/resources/ review-manuscript-ce-video.aspx. 